Article

\title{
Design, Synthesis, Characterization and Computational Evaluation of Novel Isobutychalcones as Cytotoxic Agents: Part-A
}

\author{
Afzal Basha Shaik ${ }^{1, *}$, Yejella Rajendra Prasad ${ }^{1}$ and Shaik Shahanaaz ${ }^{2}$ \\ 1 A.U College of Pharmaceutical Sciences, Andhra University, \\ 53000 Andhra Pradesh, India; dryrp_au@rediffmail.com \\ 2 Department of Pharmaceutical Analysis, Victoria College of Pharmacy, \\ 522001 Andhra Pradesh, India; shahanaazpharmacy@gmail.com \\ * Correspondence: bashafoye@gmail.com
}

\begin{abstract}
A series of novel isobutylchalcones (A1-A20) were prepared, evaluated for their cytotoxic activity and characterized by FTIR, ${ }^{1} \mathrm{H}$ NMR, ${ }^{13} \mathrm{C}$ NMR, and elemental analysis data. The logic behind the design is to synthesize and compare chalcones containing electron releasing lipophilic isobutyl substituent on aromatic ring A and the B ring with aromatic ring containing a range of electron releasing and electron withdrawing groups as well as heteroaromatic rings for their cytotoxic activity. The compounds were tested against HT-29 (colon cancer), MCF-7 (breast cancer) and DU-145 (prostate cancer) cell lines using methotrexate (IC50 $12 \pm 1$ (HT-29), $9 \pm 1$ (MCF-7) $5 \pm 1$ (DU-145)) as reference standard. Compound A6 having 2,4-difluorphenyl moiety was most potent of the series against all the three cell lines and notably A6 was mainly effective against DU-145 cell lines with an IC50 value of $18 \mu \mathrm{g} / \mathrm{mL}$. The critical structural features required for the activity against all the cell lines were identified through pharmacophore model using $\mathrm{PHASE}^{\mathrm{TM}}$ which has recognised a 5 point AHHRR model and is consistent with the cytotoxic activity of the tested compounds.
\end{abstract}

Keywords: chalcone; cytotoxic activity; pharmacophore model

\section{Introduction}

Cancer is uncontrolled growth of cells, which can invade and spread to distant sites of the body and is one of the most difficult afflictions in the world [1, 2]. According to World Health Organization (WHO) cancer figures among the leading causes of morbidity and mortality worldwide, with approximately 14 million new cases and 8.2 million cancer related deaths in 2012 [3] and the number of new cases is expected to rise by about $70 \%$ over the next 2 decades. Among men, the 5 most common sites of cancer diagnosed in 2012 were lung, prostate, colorectal, stomach, and liver cancer and among the women were breast, colorectal, lung, cervix, and stomach cancer. Despite of the availability of advanced chemotherapeutic agents, the treatment of cancer is challenging because of objectionable side effects of existing cytotoxic agents and also lack of selectivity for tumour cells as a dose of anticancer drug sufficient to kill tumour cells is often toxic to the normal tissue and leads to many side effects, which in turn, limits its treatment efficacy. Development of resistance against the existing anticancer drugs keeps research window open in the search of newer 
chemotherapeutics [4]. Hence, there is a hunger for the development of novel compounds with high usefulness, fewer side effects, devoid of resistance and superior selectivity.

Chalcones are a class of natural $\alpha, \beta$-unsaturated enones [5-7] biosynthesized by means of polyketide pathway and are the intermediates for flavonoids biosynthesis [8]. These compounds possess broad array of pharmacological activities $[9,10]$ and specifically emerged as potential anticancer agents in the last 15 years [11]. Several pure chalcones have been approved for clinical use in humans. Clinical trials have shown that these compounds reached reasonable plasma concentration, well-tolerated [12] and have less chance to interact with DNA, which omits the risk of mutagenicity, a key problem with many anticancer agents [13]. They are absorbed through daily diet and show promising cancer chemopreventive role [14]. Cytotoxic and anticancer activities are mediated by modulating important molecular pathways or targets including, P-glycoprotein-mediated multidrug resistance, m-TOR pathway, $\beta$-catenin degradation, STAT3, tumour vasculature, cell death induction, tubulin polymerization inhibition, NF-kappa B pathway, androgen and estrogen receptor signalling, p53 pathway etc., [15]. Aforementioned properties motivated us to synthesize and evaluate chalcones as potential cytotoxic agents.

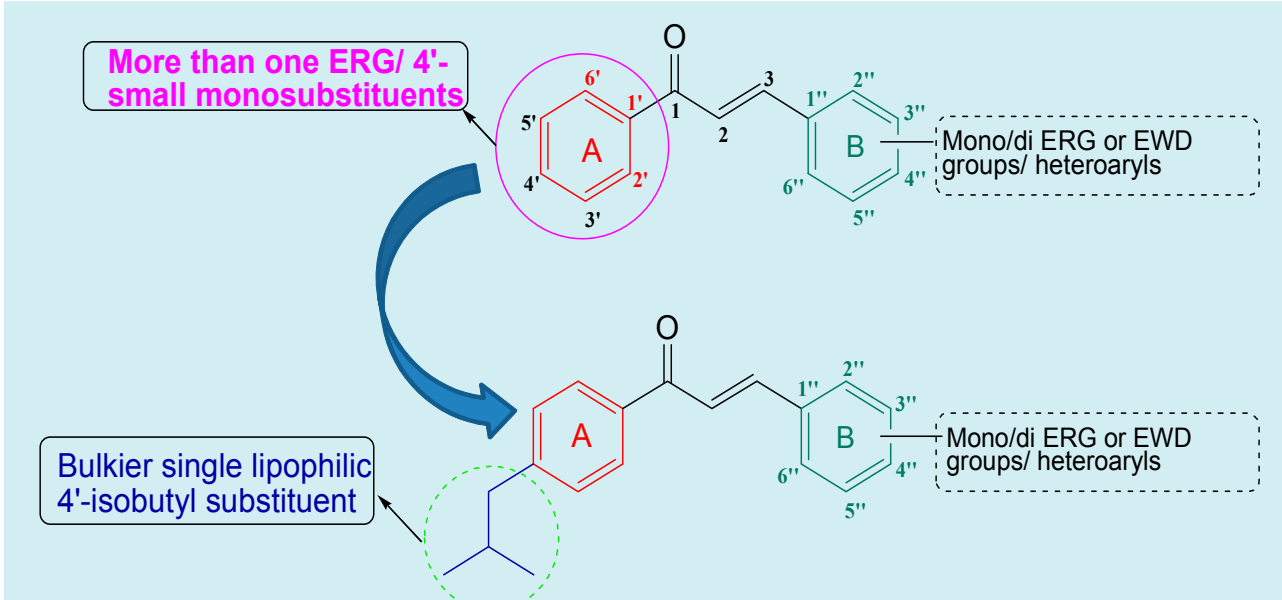

Figure 1. Designing stategy of the test compounds $(\mathbf{A 1 - A 2 0}) . \mathrm{ERG}=$ Electron releasing groups; $\mathrm{EWG}=$ Electron withdrawing groups

A range of chalcones with altered functionalities linked to $\alpha, \beta$-unsaturated carbonyl system, proved as active anticancer agents. In particular incorporation of multiple electron releasing groups on ring-A with single or multiple electron releasing (or withdrawing) groups on ringB [16], replacement of aryl rings with heteroaryl(s) [17], rigidification of keto vinyl arrangement to form chalconoids [18]. To the best of our knowledge most of the chalcones reported with anticancer action, both from the nature and synthesis typically contain more than one electron releasing group on ring-A [19-24], and even if monosubstitution is present it is either a simple $-\mathrm{NH}_{2},-\mathrm{OH},-\mathrm{OCH}_{3}$ and $-\mathrm{CH}_{3}$ [25-27], but not a bulkier hydrophobic isobutyl functionality. Lipophilicity plays a crucial role in cell permeability and presence of such groups increase the penetrability and inhibitory effects of compounds against cancer cells. Hence we premeditated to design and study the effect of monosubstituted ring-A with 4 '-isobutyl by conserving the same with changing ring-B portion (Fig. 1). 


\section{Materials and methods}

\subsection{General}

All chemical reagents and solvents were purchased from S.D Fine Chem. Ltd, Mumbai, India. 4-isobutylacetophenone was purchased from Aldrich Chemical Co. (Melwaukee, Wisconsin, USA). Reactions were monitored by TLC using silica gel-G (Merck grade) as the adsorbent. All the melting points were determined in open capillaries, using Boitus melting point apparatus, expressed in ${ }^{\circ} \mathrm{C}$ and are uncorrected. The IR spectra were recorded on Bruker Vertex $80 \mathrm{v}$ spectrometer using potassium bromide disks. ${ }^{1} \mathrm{H}$ and ${ }^{13} \mathrm{C}$ NMR spectra were recorded on Bruker AMX $400 \mathrm{MHz}$ NMR spectrophotometer using TMS as an internal standard and the chemical shifts $(\delta)$ are expressed in ppm. Elemental analyses were carried out using a Carlo Erba 1108 elemental analyzer for $\mathrm{C}, \mathrm{H}$, and $\mathrm{N}$ and the results are within \pm $0.4 \%$ of the calculated values. HT-29 (colon), MCF-7 (breast) and DU-145 (prostate) cancer cell lines were obtained from National Centre for Cell Science (NCCS), Pune, India. DMEM (Dulbeccos Modified Eagels Medium), MEM (Minimum Essential Media Eagle), MTT [3(4,5-dimethylthiazol-2-yl)-2,5-diphenyltetrazolium bromide], Trypsin, EDTA were purchased from Sigma chemicals (St.Louis, MO). Fetal bovine serum (FBS) was purchased from Arrow Labs and 96 well flat bottom tissue culture plates were purchased from Tarsons Products Pvt. Ltd, Kolkata, India.

\subsection{Chemistry}

2.2.1 General method of synthesis of isobutylchalcones: A mixture of 1-(4isobutylphenyl)ethanone $(0.001 \mathrm{~mole})$ and the appropriate aryl or heteroaryl aldehyde $(0.001$ mole) was stirred in ethanol $(7.5 \mathrm{~mL})$ and an aqueous solution of $\mathrm{KOH}(50 \%, 7.5 \mathrm{~mL})$ was added drop wise. The mixture was set aside for $24 \mathrm{~h}$ at room temperature, acidified with mixture of hydrochloric acid and water (1:1), to attain the precipitate of chalcones (A1-A20). The chalcones were then filtered under vacuum, washed with water and dried. Purity of the compounds was checked using TLC and impure chalcones were recrystallized from ethanol to obtain the pure compounds (Scheme 1).<smiles>CC(=O)c1ccc(CC(C)C)cc1</smiles>

(1)

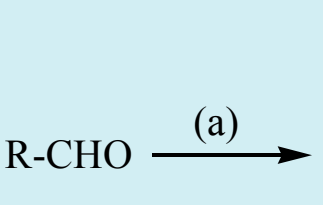

(2)<smiles>[R]C=CC(=O)c1ccc(CC(C)C)cc1</smiles>

(A1-A20)

Scheme 1 Synthesis of chalcones A1-A20. Reagents and conditions: (a) ethanol, $\mathrm{KOH}$, room temparature; (1) 1-(4-isobutylphenyl)ethanone (2) aromatic or heteroaromatic aldehyde

2.2.2. (E)-1-(4'-isobutylyphenyl)-3-(4"-chlorophenyl)-2-propen-1-one (A1): Yield 92\%; m.p. $136-138^{\circ} \mathrm{C}$; IR $\left(\mathrm{KBr}, \mathrm{cm}^{-1}\right)$ : $1659(\mathrm{C}=\mathrm{O}), 1585(\mathrm{C}=\mathrm{C}$ of $\mathrm{Ar}), 1505(\mathrm{CH}=\mathrm{CH}), 835(\mathrm{C}-$ $\mathrm{Cl}), 3050$ (Ar C-H), 2833 (Alkyl C-H); ${ }^{1} \mathbf{H}$ NMR (400 MHz, CDCl, $\left.\mathrm{ppm}\right): \delta 7.39(1 \mathrm{H}, \mathrm{d}, J=$ $17 \mathrm{~Hz},-\mathrm{CO}-\mathrm{CH}=), 7.74(1 \mathrm{H}, \mathrm{d}, J=17 \mathrm{~Hz},=\mathrm{CH}-\mathrm{Ar}), 7.19-7.91(8 \mathrm{H}, \mathrm{Ar}-\mathrm{H}), 0.92(6 \mathrm{H}, \mathrm{d}, J=8$ $\left.\mathrm{Hz},-\left(\mathrm{CH}_{3}\right)_{2}\right), 1.75-1.95(1 \mathrm{H}, \mathrm{m},-\mathrm{CH}-), 2.72\left(2 \mathrm{H}, \mathrm{d}, J=8 \mathrm{~Hz},-\mathrm{CH}_{2}-\right) ;{ }^{13} \mathbf{C} \mathbf{N M R}(400 \mathrm{MHz}$, 
$\left.\mathrm{CDCl}_{3}, \mathrm{ppm}\right): \delta 189.77$ (C-1), 122.65 (C-2), 142.79 (C-3), 129.41 (C-2' and C-6'), $129.52(\mathrm{C}-$ $3^{\prime}$ and C-5'), 135.79 (C-1'), 147.53 (C-4'), 133.58 (C-1"), 138.12 (C-4"), 128.50 (C-2" and C6"), 129.22 (C-3" and $\mathrm{C}-5 "), 22.33\left(-\mathrm{CH}_{3}, \mathrm{C}\right.$ of isobutyl group at $\left.\mathrm{C}-4 "\right), 30.12$ (-CH-, $\mathrm{C}$ of isobutyl group at $\mathrm{C}-4 "), 45.45\left(-\mathrm{CH}_{2}-, \mathrm{C}\right.$ of isobutyl group at $\left.\mathrm{C}-4 "\right)$; Anal. Calcd for: $\mathrm{C}_{19} \mathrm{H}_{19} \mathrm{ClO}$ : C, 76.37; H, 6.41; Found: C, 76.40; H, 6.44.

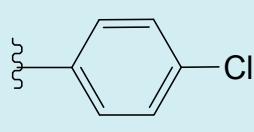

A1

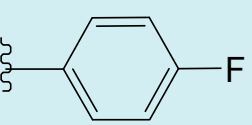

A5

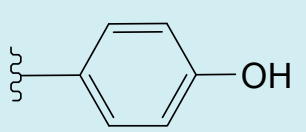

A9

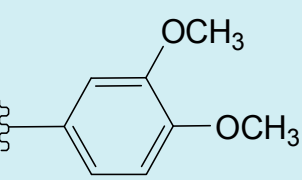

A13

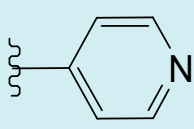

A17

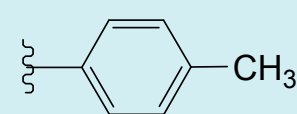

A2

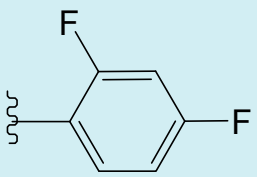

A6

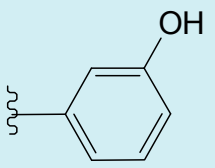

A10

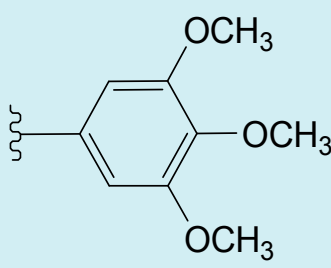

A14<smiles>Cc1ccc[nH]1</smiles>

A18

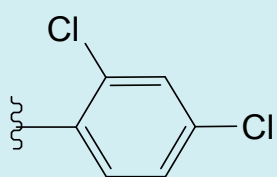

A3<smiles>Cc1ccc(N(C)C)cc1</smiles>

A7

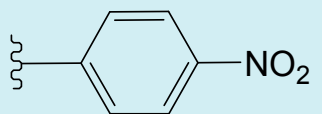

A11

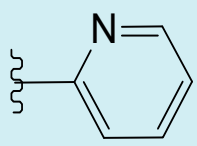

A15<smiles>[TeH]c1cccs1</smiles>

A19

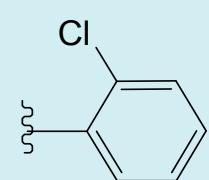

A4

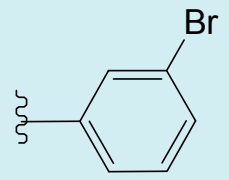

A8

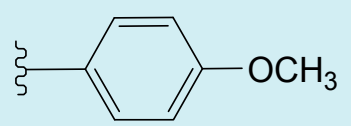

A12

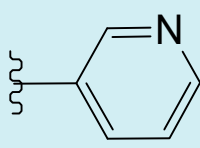

A16<smiles>Brc1ccc(CCCCc2ccco2)o1</smiles>

A20

Figure 2. Different aldehydes selected for synthesis; A1 to A20 are the codes of 20 chalcones. 
2.2.3. (E)-1-(4'-isobutylphenyl)-3-(4"-methylphenyl)-2-propen-1-one (A2): Yield 87\%; m.p. $128-130{ }^{\circ} \mathrm{C}$; IR $\left(\mathrm{KBr}, \mathrm{cm}^{-1}\right): 1655(\mathrm{C}=\mathrm{O}), 1602(\mathrm{C}=\mathrm{C}$ of $\mathrm{Ar}), 1505(\mathrm{CH}=\mathrm{CH}), 3010(\mathrm{Ar}$ C-H), 2921 (Alkyl C-H); ${ }^{1} \mathbf{H}$ NMR (400 MHz, CDCl $\left.3, \mathrm{ppm}\right): \delta 2.30\left(3 \mathrm{H}, \mathrm{s}, \mathrm{Ar}_{-} \mathrm{CH}_{3}\right), 7.25$ $(1 \mathrm{H}, \mathrm{d}, J=17 \mathrm{~Hz},-\mathrm{CO}-\mathrm{CH}=), 7.65(1 \mathrm{H}, \mathrm{d}, J=17 \mathrm{~Hz},=\mathrm{CH}-\mathrm{Ar}), 6.83-7.82(8 \mathrm{H}, \mathrm{Ar}-\mathrm{H}), 0.89$ $\left(6 \mathrm{H}, \mathrm{d}, J=8 \mathrm{~Hz},-\left(\mathrm{CH}_{3}\right)_{2}\right), 1.70-1.92(1 \mathrm{H}, \mathrm{m},-\mathrm{CH}-), 2.65\left(2 \mathrm{H}, \mathrm{d}, J=8 \mathrm{~Hz},-\mathrm{CH}_{2-}\right) ;{ }^{13} \mathbf{C} \mathbf{~ N M R}$ (400 MHz, $\left.\mathrm{CDCl}_{3}, \mathrm{ppm}\right): \delta 188.67$ (C-1), 121.65 (C-2), 140.97 (C-3), 126.51 (C-2' and C-6'), 128.22 (C-3' and C-5'), 132.12 (C-1'), 137.63 (C-4'), 134.89 (C-1"), 145.12 (C-4"), 127.09 (C$2^{\prime \prime}$ and C-6"), 129.1 (C-3" and C-5"), $22.80\left(-\mathrm{CH}_{3}, \mathrm{C}\right.$ of isobutyl group at C-4"), 29.12 (-CH-, C of isobutyl group at C-4"), $45.72\left(-\mathrm{CH}_{2-}, \mathrm{C}\right.$ of isobutyl group at $\left.\mathrm{C}-4 "\right), 24.35\left(-\mathrm{CH}_{3} \mathrm{C}\right.$ at C-4"); Anal. Calcd for: $\mathrm{C}_{20} \mathrm{H}_{22} \mathrm{O}$ : C, 86.29; H, 7.97; Found: C, 86.32; H, 7.99.

2.2.4. (E)-1-(4'-isobutylphenyl)-3-(2",4"-dichlorophenyl)-2-propen-1-one (A3): Yield 85\%; m.p. $149-151^{\circ} \mathrm{C}$; IR $\left(\mathrm{KBr}, \mathrm{cm}^{-1}\right): 1655(\mathrm{C}=\mathrm{O}), 1581(\mathrm{C}=\mathrm{C}$ of $\mathrm{Ar}), 1510(\mathrm{CH}=\mathrm{CH}), 833(\mathrm{C}-$ $\mathrm{Cl}), 3057$ (Ar C-H), 2877 (Alkyl C-H); ${ }^{1} \mathbf{H}$ NMR (400 MHz, CDCl, ppm): $\delta 7.42(1 \mathrm{H}, \mathrm{d}, J=$ $17 \mathrm{~Hz},-\mathrm{CO}-\mathrm{CH}=), 7.84(1 \mathrm{H}, \mathrm{d}, J=17 \mathrm{~Hz},=\mathrm{CH}-\mathrm{Ar}), 7.20-8.20(7 \mathrm{H}, \mathrm{Ar}-\mathrm{H}), 1.11(6 \mathrm{H}, \mathrm{d}, J=8$ $\left.\mathrm{Hz},-\left(\mathrm{CH}_{3}\right)_{2}\right), 1.99-2.13(1 \mathrm{H}, \mathrm{m},-\mathrm{CH}-), 2.73\left(2 \mathrm{H}, \mathrm{d}, J=8 \mathrm{~Hz},-\mathrm{CH}_{2}-\right) ;{ }^{13} \mathbf{C}$ NMR $(400 \mathrm{MHz}$, $\left.\mathrm{CDCl}_{3}, \mathrm{ppm}\right): \delta 190.11(\mathrm{C}-1), 121.78(\mathrm{C}-2), 141.21$ (C-3), 130.03 (C-2' and C-6'), $130.35(\mathrm{C}-$ $3^{\prime}$ and C-5'), 134.25 (C-1'), 147.63 (C-4'), 132.71 (C-1"), 135.27 (C-4"), 132.69 (C-2"), 129.23 (C-6"), 130.79 (C-3"), 126.72 (C-5"), $23.11\left(-\mathrm{CH}_{3}, \mathrm{C}\right.$ of isobutyl group at C-4"), 29.31 (-CH-, C of isobutyl group at $\mathrm{C}-4 "), 45.91$ (- $\mathrm{CH}_{2}-, \mathrm{C}$ of isobutyl group at $\left.\mathrm{C}-4 "\right)$; Anal. Calcd for: $\mathrm{C}_{19} \mathrm{H}_{18} \mathrm{Cl}_{2} \mathrm{O}$ : C, 68.48; H, 5.44; Found: C, 68.53; H, 5.49.

2.2.5. (E)-1-(4'-isobutylyphenyl)-3-(2"-chlorophenyl)-2-propen-1-one (A4): Yield 65\%; m.p. $140-142{ }^{\circ} \mathrm{C}$; IR $\left(\mathrm{KBr}, \mathrm{cm}^{-1}\right)$ : $1652(\mathrm{C}=\mathrm{O}), 1583(\mathrm{C}=\mathrm{C}$ of $\mathrm{Ar}), 1502(\mathrm{CH}=\mathrm{CH}), 833(\mathrm{C}-$ $\mathrm{Cl}), 3120$ (Ar C-H), 2920 (Alkyl C-H); ${ }^{1} \mathbf{H}$ NMR (400 MHz, CDCl $\left.3, \mathrm{ppm}\right): \delta 7.31(1 \mathrm{H}, \mathrm{d}, J=$ $17 \mathrm{~Hz},-\mathrm{CO}-\mathrm{CH}=), 7.74(1 \mathrm{H}, \mathrm{d}, J=17 \mathrm{~Hz},=\mathrm{CH}-\mathrm{Ar}), 6.87-7.91(8 \mathrm{H}, \mathrm{Ar}-\mathrm{H}), 1.02(6 \mathrm{H}, \mathrm{d}, J=8$ $\left.\mathrm{Hz},-\left(\mathrm{CH}_{3}\right)_{2}\right), 2.22-2.44(1 \mathrm{H}, \mathrm{m},-\mathrm{CH}-), 2.66\left(2 \mathrm{H}, \mathrm{d}, J=8 \mathrm{~Hz},-\mathrm{CH}_{2}-\right) ;{ }^{13} \mathbf{C}$ NMR $(400 \mathrm{MHz}$, $\left.\mathrm{CDCl}_{3}, \mathrm{ppm}\right): \delta 189.44(\mathrm{C}-1), 121.42(\mathrm{C}-2), 145.15(\mathrm{C}-3), 128.5$ (C-2' and C-6'), 129.5 (C-3' and C-5'), 133.22 (C-1'), 146.71 (C-4'), 133.91 (C-1"), 129.55 (C-4"), 128.85 (C-2"), 130.64 (C-6"), 128.8 (C-3"), 126.2 (C-5"), 22.21 (-CH3, C of isobutyl group at C-4"), 29.11 (-CH-, C of isobutyl group at $\mathrm{C}-4 "), 45.71\left(-\mathrm{CH}_{2}-, \mathrm{C}\right.$ of isobutyl group at $\left.\mathrm{C}-4 "\right)$; Anal. Calcd for: $\mathrm{C}_{19} \mathrm{H}_{19} \mathrm{ClO}$ : C, 76.37; H, 6.41; Found: C, 76.42; H, 6.50.

2.2.6. (E)-1-(4'-isobutylphenyl)-3-(4"-fluorophenyl)-2-propen-1-one (A5): Yield 85\%; m.p. 142-144 ${ }^{\circ} \mathrm{C}$; IR $\left(\mathrm{KBr}, \mathrm{cm}^{-1}\right)$ : $1664(\mathrm{C}=\mathrm{O}), 1580(\mathrm{C}=\mathrm{C}$ of $\mathrm{Ar}), 1524(\mathrm{CH}=\mathrm{CH}), 928(\mathrm{C}-\mathrm{F})$, 3127 (Ar C-H), 2954 (Alkyl C-H); ${ }^{1} \mathbf{H}$ NMR (400 MHz, CDCl $\left.3, \mathrm{ppm}\right): \delta 7.57(1 \mathrm{H}, \mathrm{d}, J=17$ $\mathrm{Hz},-\mathrm{CO}-\mathrm{CH}=), 7.87(1 \mathrm{H}, \mathrm{d}, J=17 \mathrm{~Hz},=\mathrm{CH}-\mathrm{Ar}), 7.33-8.12(8 \mathrm{H}, \mathrm{Ar}-\mathrm{H}), 1.00(6 \mathrm{H}, \mathrm{d}, J=8$ $\left.\mathrm{Hz},-\left(\mathrm{CH}_{3}\right)_{2}\right), 1.80-2.04(1 \mathrm{H}, \mathrm{m},-\mathrm{CH}-), 2.75\left(2 \mathrm{H}, \mathrm{d}, J=8 \mathrm{~Hz},-\mathrm{CH}_{2}-\right) ;{ }^{13} \mathbf{C}$ NMR $(400 \mathrm{MHz}$, $\left.\mathrm{CDCl}_{3}, \mathrm{ppm}\right): \delta 190.21$ (C-1), 124.52 (C-2), 145.29 (C-3), 129.44 (C-2' and C-6'), 129.67 (C$3^{\prime}$ and C-5'), 135.92 (C-1'), 144.76 (C-4'), 131.8 (C-1"), 163.12 (C-4"), 129.11 (C-2" and C-6"), 118.98 (C-3" and C-5"), $22.82\left(-\mathrm{CH}_{3}, \mathrm{C}\right.$ of isobutyl group at C-4"), 29.57 (-CH-, C of isobutyl group at C-4"), $45.91\left(-\mathrm{CH}_{2-}, \mathrm{C}\right.$ of isobutyl group at C-4"); Anal. Calcd for: $\mathrm{C}_{19} \mathrm{H}_{19} \mathrm{FO}$ : $\mathrm{C}$, 80.82; H, 6.78; Found: C, 80.86; H, 6.85.

2.2.7. (E)-1-(4'-isobutylphenyl)-3-(2",4"-difluorophenyl)-2-propen-1-one (A6): Yield 79\%; m.p. $163-165^{\circ} \mathrm{C}$; IR $\left(\mathrm{KBr}, \mathrm{cm}^{-1}\right): 1655(\mathrm{C}=\mathrm{O}), 1581(\mathrm{C}=\mathrm{C}$ of $\mathrm{Ar}), 1510(\mathrm{CH}=\mathrm{CH}), 925(\mathrm{C}-$ F), 926 (C-F), 3040 (Ar C-H), 2933 (Alkyl C-H); ${ }^{1} \mathbf{H}$ NMR (400 MHz, CDCls, ppm): $\delta 7.49$ $(1 \mathrm{H}, \mathrm{d}, J=17 \mathrm{~Hz},-\mathrm{CO}-\mathrm{CH}=), 7.99(1 \mathrm{H}, \mathrm{d}, J=17 \mathrm{~Hz},=\mathrm{CH}-\mathrm{Ar}), 7.11-8.20(7 \mathrm{H}, \mathrm{Ar}-\mathrm{H}), 1.19$ $\left(6 \mathrm{H}, \mathrm{d}, J=8 \mathrm{~Hz},-\left(\mathrm{CH}_{3}\right)_{2}\right), 2.10-2.41(1 \mathrm{H}, \mathrm{m},-\mathrm{CH}-), 2.91\left(2 \mathrm{H}, \mathrm{d}, J=8 \mathrm{~Hz},-\mathrm{CH}_{2}-\right) ;{ }^{13} \mathbf{C} \mathbf{N M R}$ (400 MHz, $\left.\mathrm{CDCl}_{3}, \mathrm{ppm}\right): \delta 190.23$ (C-1), 122.1 (C-2), 146.2 (C-3), 134.8 (C-2' and C-6'), 129.52 (C-3' and C-5'), 134.55 (C-1'), 147.29 (C-4'), 134.11 (C-1"), 165.42 (C-4"), 159.51 (C- 
2"), 129.6 (C-6"), 109.29 (C-3"), 112.0 (C-5"), 23.21 (-CH3, C of isobutyl group at C-4"), 30.12 (-CH-, $\mathrm{C}$ of isobutyl group at C-4"), $45.81\left(-\mathrm{CH}_{2}-, \mathrm{C}\right.$ of isobutyl group at C-4"); Anal. Calcd for: $\mathrm{C}_{19} \mathrm{H}_{19} \mathrm{FO}$ : C, 75.98; H, 6.04; Found: C, 76.03; H, 6.06.

2.2.8. (E)-1-(4'-isobutylphenyl)-3-(4"-dimethylaminophenyl)-2-propen-1-one (A7): Yield 82\%; m.p. $138-140{ }^{\circ} \mathrm{C}$; IR $\left(\mathrm{KBr}, \mathrm{cm}^{-1}\right): 1650(\mathrm{C}=\mathrm{O}), 1586(\mathrm{C}=\mathrm{C}$ of $\mathrm{Ar}), 1505(\mathrm{CH}=\mathrm{CH})$, $1178\left(-\mathrm{N}\left(\mathrm{CH}_{3}\right)_{2}\right), 3198$ (Ar C-H), 2940 (Alkyl C-H); ${ }^{1} \mathbf{H}$ NMR (400 MHz, $\left.\mathrm{CDCl}_{3}, \mathrm{ppm}\right): \delta$ $3.10\left(6 \mathrm{H}, \mathrm{s},-\mathrm{N}\left(\mathrm{CH}_{3}\right)_{2}\right), 7.29(1 \mathrm{H}, \mathrm{d}, J=17 \mathrm{~Hz},-\mathrm{CO}-\mathrm{CH}=), 7.75(1 \mathrm{H}, \mathrm{d}, J=17 \mathrm{~Hz},=\mathrm{CH}-\mathrm{Ar})$, 6.64-8.10 (8H, Ar-H), $0.98\left(6 \mathrm{H}, \mathrm{d}, J=8 \mathrm{~Hz},-\left(\mathrm{CH}_{3}\right)_{2}\right), 2.19-2.33(1 \mathrm{H}, \mathrm{m},-\mathrm{CH}-), 2.58(2 \mathrm{H}, \mathrm{d}$, $\left.J=8 \mathrm{~Hz},-\mathrm{CH}_{2-}\right) ;{ }^{13} \mathrm{C}$ NMR (400 MHz, $\left.\mathrm{CDCl}_{3}, \mathrm{ppm}\right): \delta 186.61$ (C-1), $120.10(\mathrm{C}-2), 144.65$ (C-3), 130.11 (C-2' and C-6'), 128.45 (C-3' and C-5'), 135.67 (C-1'), 146.81 (C-4'), 133.31 (C1") 167.22 (C-4"), 159.51 (C-2"), 129.61 (C-6"), 109.29 (C-3"), 111.03 (C-5"), 23.10 (-CH3, C of isobutyl group at C-4"), $30.33(-\mathrm{CH}-, \mathrm{C}$ of isobutyl group at $\mathrm{C}-4 "), 45.99\left(-\mathrm{CH}_{2-}, \mathrm{C}\right.$ of isobutyl group at C-4"), $40.33\left(-\mathrm{N}\left(\mathrm{CH}_{3}\right)_{2}\right.$,); Anal. Calcd for: $\mathrm{C}_{21} \mathrm{H}_{25} \mathrm{NO}: \mathrm{C}, 82.04 ; \mathrm{H}, 8.20$; N, 4.56; Found: C, 82.09; H, 8.23; N, 4.59 .

2.2.9. (E)-1-(4'-isobutylphenyl)-3-(3"-bromophenyl)-2-propen-1-one (A8): Yield 80\%; m.p. $107-109^{\circ} \mathrm{C}$; IR $\left(\mathrm{KBr}, \mathrm{cm}^{-1}\right): 1650(\mathrm{C}=\mathrm{O}), 1605(\mathrm{C}=\mathrm{C}$ of $\mathrm{Ar}), 1502(\mathrm{CH}=\mathrm{CH}), 969(\mathrm{C}-$ $\mathrm{Br}), 3155$ (Ar C-H), 2836 (Alkyl C-H); ${ }^{1} \mathbf{H}$ NMR (400 MHz, CDCl $\left.3, \mathrm{ppm}\right): \delta 7.36(1 \mathrm{H}, \mathrm{d}, J=$ $17 \mathrm{~Hz},-\mathrm{CO}-\mathrm{CH}=), 7.79(1 \mathrm{H}, \mathrm{d}, J=17 \mathrm{~Hz},=\mathrm{CH}-\mathrm{Ar}), 7.19-8.09(8 \mathrm{H}, \mathrm{Ar}-\mathrm{H}), 1.01(6 \mathrm{H}, \mathrm{d}, J=8$ $\left.\mathrm{Hz},-\left(\mathrm{CH}_{3}\right)_{2}\right), 2.02-2.20(1 \mathrm{H}, \mathrm{m},-\mathrm{CH}-), 2.58\left(2 \mathrm{H}, \mathrm{d}, J=8 \mathrm{~Hz},-\mathrm{CH}_{2}-\right) ;{ }^{13} \mathbf{C}$ NMR $(400 \mathrm{MHz}$, $\left.\mathrm{CDCl}_{3}, \mathrm{ppm}\right): \delta 189.37$ (C-1), 123.09 (C-2), 146.27 (C-3), 131.21 (C-2' and C-6'), $129.27(\mathrm{C}-$ $3^{\prime}$ and C-5'), 136.13 (C-1'), 146.28 (C-4'), 137.42 (C-1"), 131.12 (C-4"and C-5"), 130.54 (C-2"), 124.43 (C-6"), 127.67 (C-3"), $22.92\left(-\mathrm{CH}_{3}, \mathrm{C}\right.$ of isobutyl group at $\left.\mathrm{C}-4 "\right), 30.12$ (-CH-, $\mathrm{C}$ of isobutyl group at $\mathrm{C}-4 "), 45.61\left(-\mathrm{CH}_{2}-, \mathrm{C}\right.$ of isobutyl group at $\left.\mathrm{C}-4 "\right)$; Anal. Calcd for: $\mathrm{C}_{19} \mathrm{H}_{19} \mathrm{BrO}$ : C, 66.48; H, 5.58; Found: C, 66.53; H, 5.63.

2.2.10. (E)-1-(4'-isobutylphenyl)-3-(4"-hydroxyphenyl)-2-propen-1-one (A9): Yield 73\%; m.p. $156-158{ }^{\circ} \mathrm{C}$; IR $\left(\mathrm{KBr}, \mathrm{cm}^{-1}\right)$ : $3460(\mathrm{O}-\mathrm{H}), 1648(\mathrm{C}=\mathrm{O}), 1606(\mathrm{C}=\mathrm{C}$ of $\mathrm{Ar}), 1505$ $(\mathrm{CH}=\mathrm{CH}), 3060(\mathrm{Ar} \mathrm{C}-\mathrm{H}), 2852\left(\right.$ Alkyl C-H); ${ }^{1} \mathbf{H}$ NMR (400 MHz, $\left.\mathrm{CDCl}_{3}, \mathrm{ppm}\right): \delta 4.92$ $(1 \mathrm{H}, \mathrm{Ar}-\mathrm{OH}), 7.29(1 \mathrm{H}, \mathrm{d}, J=17 \mathrm{~Hz},-\mathrm{CO}-\mathrm{CH}=), 7.80(1 \mathrm{H}, \mathrm{d}, J=17 \mathrm{~Hz},=\mathrm{CH}-\mathrm{Ar}), 7.61-8.02$ $(8 \mathrm{H}, \mathrm{Ar}-\mathrm{H}), 1.02\left(6 \mathrm{H}, \mathrm{d}, J=8 \mathrm{~Hz},-\left(\mathrm{CH}_{3}\right)_{2}\right), 1.92-2.01(1 \mathrm{H}, \mathrm{m},-\mathrm{CH}-), 2.40(2 \mathrm{H}, \mathrm{d}, J=8 \mathrm{~Hz}$, $\left.-\mathrm{CH}_{2-}\right) ;{ }^{13} \mathbf{C}$ NMR $\left(400 \mathrm{MHz}, \mathrm{CDCl}_{3}, \mathrm{ppm}\right): \delta 188.52$ (C-1), 122.87 (C-2), 148.32 (C-3), 131.26 (C-2' and C-6'), 128.91 (C-3' and C-5'), 134.99 (C-1'), 145.56 (C-4'), 133.54 (C-1'), $159.35(\mathrm{C}-4 "), 129.11\left(\mathrm{C}-2^{\prime \prime}\right.$ and $\left.\mathrm{C}-6 "\right), 120.21$ (C-3" and $\left.\mathrm{C}-5^{\prime \prime}\right), 23.45\left(-\mathrm{CH}_{3}, \mathrm{C}\right.$ of isobutyl group at C-4'), 29.92 (-CH-, $\mathrm{C}$ of isobutyl group at C-4'), $44.99\left(-\mathrm{CH}_{2}-, \mathrm{C}\right.$ of isobutyl group at C-4'); Anal. Caled for: $\mathrm{C}_{19} \mathrm{H}_{19} \mathrm{O}_{2}$ : C, 81.40; H, 7.19; Found: C, 81.45; H, 7.24.

2.2.11. (E)-1-(4'-isobutylphenyl)-3-(3"-hydroxyphenyl)-2-propen-1-one (A10): Yield 65\%; m.p. $152-154{ }^{\circ} \mathrm{C}$; IR $\left(\mathrm{KBr}, \mathrm{cm}^{-1}\right)$ : $3520(\mathrm{O}-\mathrm{H}), 1648(\mathrm{C}=\mathrm{O}), 1612(\mathrm{C}=\mathrm{C}$ of $\mathrm{Ar}), 1505$ $(\mathrm{CH}=\mathrm{CH}), 3111(\mathrm{Ar} \mathrm{C}-\mathrm{H}), 2928$ (Alkyl C-H); ${ }^{1} \mathbf{H}$ NMR (400 MHz, $\left.\mathrm{CDCl}_{3}, \mathrm{ppm}\right): \delta 4.80$ $(1 \mathrm{H}, \mathrm{Ar}-\mathrm{OH}), 7.26(1 \mathrm{H}, \mathrm{d}, J=17 \mathrm{~Hz},-\mathrm{CO}-\mathrm{CH}=), 7.71(1 \mathrm{H}, \mathrm{d}, J=17 \mathrm{~Hz},=\mathrm{CH}-\mathrm{Ar}), 6.85-8.00$ $(8 \mathrm{H}, \mathrm{Ar}-\mathrm{H}), 1.01\left(6 \mathrm{H}, \mathrm{d}, J=8 \mathrm{~Hz},-\left(\mathrm{CH}_{3}\right)_{2}\right), 2.19-2.31(1 \mathrm{H}, \mathrm{m},-\mathrm{CH}-), 2.45(2 \mathrm{H}, \mathrm{d}, J=8 \mathrm{~Hz},-$ $\left.\mathrm{CH}_{2-}\right) ;{ }^{13} \mathrm{C}$ NMR (400 MHz, $\left.\mathrm{CDCl}_{3}, \mathrm{ppm}\right): \delta 188.96$ (C-1), 123.13 (C-2), 148.77 (C-3), 132.11 (C-2' and C-6'), 129.56 (C-3' and C-5'), 135.43 (C-1'), 146.12 (C-4'), 136.62 (C-1"), 115.21 (C-2"), 159.43 (C-3"), 118.46 (C-4"), 130.13 (C-5"), 120.14 (C-6"), 22.67 (-CH3, C of isobutyl group at C-4'), 29.39 (-CH-, $\mathrm{C}$ of isobutyl group at C-4'), 44.17 (- $\mathrm{CH}_{2-}, \mathrm{C}$ of isobutyl group at C-4); Anal. Calcd for: $\mathrm{C}_{19} \mathrm{H}_{19} \mathrm{O}_{2}$ : C, 81.40; H, 7.19; Found: C, 81.45; H, 7.24.

2.2.12. (E)-1-(4'-isobutylphenyl)-3-(4"-nitrophenyl)-2-propen-1-one (A11): Yield 95\%; m.p.190-192 ${ }^{\circ} \mathrm{C}$; IR (KBr, cm-1): $1652(\mathrm{C}=\mathrm{O}), 1610(\mathrm{C}=\mathrm{C}$ of $\mathrm{Ar}), 1502(\mathrm{CH}=\mathrm{CH}), 1541$ 
$\left(\mathrm{N}=\mathrm{O}\right.$, asymmetric), $1346\left(\mathrm{~N}=\mathrm{O}\right.$, symmetric), 3092 (Ar C-H), 2951 (Alkyl C-H). ${ }^{1} \mathrm{H}$ $\mathrm{NMR}(400 \mathrm{MHz}, \mathrm{CDCl} 3, \delta): 7.35(1 \mathrm{H}, \mathrm{d}, J=17 \mathrm{~Hz},-\mathrm{CO}-\mathrm{CH}=), 7.84(1 \mathrm{H}, \mathrm{d}, J=17 \mathrm{~Hz}$, $=\mathrm{CH}-\mathrm{Ar}), 7.05-7.95(8 \mathrm{H}, \mathrm{Ar}-\mathrm{H}), 0.91\left(6 \mathrm{H}, \mathrm{d}, J=8 \mathrm{~Hz},-\left(\mathrm{CH}_{3}\right)_{2}\right), 2.10-2.13(1 \mathrm{H}, \mathrm{m},-\mathrm{CH}-)$, $2.33\left(2 \mathrm{H}, \mathrm{d}, J=8 \mathrm{~Hz},-\mathrm{CH}_{2}-\right) ;{ }^{13} \mathbf{C}$ NMR $(400 \mathrm{MHz}, \mathrm{CDCl} 3): \delta 190.22$ (C-1), $123.68(\mathrm{C}-2)$, 147.56 (C-3), 133.13 (C-2' and C-6'), 131.58 (C-3' and C-5'), 137.02 (C-1'), 148.31 (C-4'), 142.41 (C-1"), 152.32 (C-4"), 128.23 (C-2" and C-6"), 122.11 (C-3" and C-5"), $22.18\left(-\mathrm{CH}_{3}, \mathrm{C}\right.$ of isobutyl group at C-4'), 28.98 (-CH-, C of isobutyl group at C-4') and $43.87\left(-\mathrm{CH}_{2}-, \mathrm{C}\right.$ of isobutyl group at C-4); Anal. Calcd for: $\mathrm{C}_{19} \mathrm{H}_{19} \mathrm{NO}_{3}$ : $\mathrm{C}, 73.77 ; \mathrm{H}, 6.19 ; \mathrm{N}, 4.53$; Found: $\mathrm{C}$, $73.80 ; \mathrm{H}, 6.24 ; \mathrm{N}, 4.59$.

2.2.13. (E)-1-(4'-isobutylphenyl)-3-(4"-methoxyphenyl)-2-propen-1-one (A12): Yield 79\%; m.p. $149-151{ }^{\circ} \mathrm{C}$; IR $\left(\mathrm{KBr}, \mathrm{cm}^{-1}\right)$ : $1655(\mathrm{C}=\mathrm{O}), 1605(\mathrm{C}=\mathrm{C}$ of $\mathrm{Ar}), 1508(\mathrm{CH}=\mathrm{CH}), 1125(-$ $\left.\mathrm{OCH}_{3}\right), 3054$ (Ar C-H), 2956 (Alkyl C-H); ${ }^{1} \mathbf{H}$ NMR (400 MHz, $\left.\mathrm{CDCl}_{3}, \mathrm{ppm}\right): \delta 3.90$ $\left(3 \mathrm{H}, \mathrm{s}, \mathrm{Ar}-\mathrm{OCH}_{3}\right), 7.19(1 \mathrm{H}, \mathrm{d}, J=17 \mathrm{~Hz},-\mathrm{CO}-\mathrm{CH}=), 7.74(1 \mathrm{H}, \mathrm{d}, J=17 \mathrm{~Hz},=\mathrm{CH}-\mathrm{Ar}), 6.71-$ $8.08(8 \mathrm{H}, \mathrm{Ar}-\mathrm{H}), 0.80\left(6 \mathrm{H}, \mathrm{d}, J=8 \mathrm{~Hz},-\left(\mathrm{CH}_{3}\right)_{2}\right), 1.62-1.84(1 \mathrm{H}, \mathrm{m},-\mathrm{CH}-), 2.09(2 \mathrm{H}, \mathrm{d}, J=8$ $\left.\mathrm{Hz},-\mathrm{CH}_{2}-\right) ;{ }^{13} \mathbf{C}$ NMR (400 MHz, $\left.\mathrm{CDCl}_{3}, \mathrm{ppm}\right): \delta 189.05$ (C-1), 121.12 (C-2), 142.97 (C-3), 127.85 (C-2' and C-6' ), 129.51 (C-3' and C-5'), 133.53 (C-1'), 143.32 (C-4'), 134.89 (C-1") 145.12 (C-4"), 127.09 (C-2" and C-6"), 115.51 (C-3" and C-5"), 22.31 (-CH3, C of isobutyl group at C-4"), 28.91 (-CH-, $\mathrm{C}$ of isobutyl group at C-4"), $44.91\left(-\mathrm{CH}_{2-}, \mathrm{C}\right.$ of isobutyl group at C-4"), $55.99\left(-\mathrm{OCH}_{3} \mathrm{C}\right.$ at C-4"); Anal. Calcd for: $\mathrm{C}_{20} \mathrm{H}_{22} \mathrm{O}_{2}: \mathrm{C}, 81.60 ; \mathrm{H}, 7.53$; Found: C, $81.65 ; \mathrm{H}, 7.57$.

2.2.14. (E)-1-(4'-isobutylphenyl)-3-(3",4"-dimethoxyphenyl)-2-propen-1-one (A13): Yield 66\%; m.p. $146-148{ }^{\circ} \mathrm{C}$; IR $\left(\mathrm{KBr}, \mathrm{cm}^{-1}\right): 1655(\mathrm{C}=\mathrm{O}), 1605(\mathrm{C}=\mathrm{C}$ of $\mathrm{Ar}), 1500(\mathrm{CH}=\mathrm{CH})$, $1130\left(-\mathrm{OCH}_{3}\right), 3066$ (Ar C-H), 2839 (Alkyl C-H); ${ }^{\mathbf{1}} \mathbf{H}$ NMR (400 MHz, CDCl $\left.3, \mathrm{ppm}\right): \delta 3.95$ $\left(6 \mathrm{H}, \mathrm{s}, 2 \mathrm{x} \mathrm{Ar}-\mathrm{OCH}_{3}\right), 7.21(1 \mathrm{H}, \mathrm{d}, J=17 \mathrm{~Hz},-\mathrm{CO}-\mathrm{CH}=), 7.80(1 \mathrm{H}, \mathrm{d}, J=17 \mathrm{~Hz},=\mathrm{CH}-\mathrm{Ar})$, 6.91-8.12 (6H, Ar-H), $1.00\left(6 \mathrm{H}, \mathrm{d}, J=8 \mathrm{~Hz},-\left(\mathrm{CH}_{3}\right)_{2}\right), 2.21-2.42(1 \mathrm{H}, \mathrm{m},-\mathrm{CH}-), 2.55(2 \mathrm{H}, \mathrm{d}$, $\left.J=8 \mathrm{~Hz},-\mathrm{CH}_{2}-\right) ;{ }^{13} \mathbf{C}$ NMR $\left(400 \mathrm{MHz}, \mathrm{CDCl}_{3}, \mathrm{ppm}\right): \delta 188.55$ (C-1), 121.01 (C-2), 142.31 (C-3), 129.61 (C-2' and C-6'), 130.74 (C-3' and C-5'), 134.20 (C-1'), 144.53 (C-4'), 128.29 (C1") 112.22 (C-2"), 149.90 (C-3" and C-4"), 115.51 (C-5"), 119.84 (C-6"), 21.71 (-CH3, C of isobutyl group at C-4"), 28.58 (-CH-,C of isobutyl group at C-4"), $43.82\left(-\mathrm{CH}_{2-}, \mathrm{C}\right.$ of isobutyl group at $\mathrm{C}-4 "), 56.71\left(-\mathrm{OCH}_{3} \mathrm{C}\right.$ at $\mathrm{C}-3$ " and $\mathrm{C}-4$ "); Anal. Calcd for: $\mathrm{C}_{20} \mathrm{H}_{22} \mathrm{O}_{2}$ : C, 77.75; $\mathrm{H}$, 7.46; Found: C, 77.77; H, 7.47.

2.2.15. (E)-1-(4'-isobutylphenyl)-3-(3",4",5"-trimethoxyphenyl)-2-propen-1-one (A14): Yield $70 \%$; m.p. $180-182^{\circ} \mathrm{C}$; IR $\left(\mathrm{KBr}, \mathrm{cm}^{-1}\right)$ : $1652(\mathrm{C}=\mathrm{O}), 1585(\mathrm{C}=\mathrm{C}$ of $\mathrm{Ar}), 1462$ $(\mathrm{CH}=\mathrm{CH}), 1127\left(-\mathrm{OCH}_{3}\right), 3110(\mathrm{Ar} \mathrm{C}-\mathrm{H}), 2853(\mathrm{Alkyl} \mathrm{C}-\mathrm{H}) ;{ }^{1} \mathbf{H}$ NMR $\left(400 \mathrm{MHz}, \mathrm{CDCl}_{3}\right.$, ppm): $\delta 3.90\left(3 \mathrm{H}, \mathrm{s}, \mathrm{Ar}-\mathrm{OCH}_{3}\right), 3.92\left(6 \mathrm{H}, \mathrm{s}, 2 \mathrm{x} \mathrm{Ar}-\mathrm{OCH}_{3}\right), 7.22(1 \mathrm{H}, \mathrm{d}, J=17 \mathrm{~Hz},-\mathrm{CO}-$ $\mathrm{CH}=), 7.53(1 \mathrm{H}, \mathrm{d}, J=17 \mathrm{~Hz},=\mathrm{CH}-\mathrm{Ar}), 6.85-8.07(6 \mathrm{H}, \mathrm{Ar}-\mathrm{H}), 1.08(6 \mathrm{H}, \mathrm{d}, J=8 \mathrm{~Hz},-$ $\left.\left(\mathrm{CH}_{3}\right)_{2}\right), 2.29-2.45(1 \mathrm{H}, \mathrm{m},-\mathrm{CH}-), 2.65\left(2 \mathrm{H}, \mathrm{d}, J=8 \mathrm{~Hz},-\mathrm{CH}_{2}-\right) ;{ }^{13} \mathbf{C}$ NMR $(400 \mathrm{MHz}$, $\left.\mathrm{CDCl}_{3}, \mathrm{ppm}\right): \delta 188.11(\mathrm{C}-1), 121.33$ (C-2), 141.86 (C-3), 128.11 (C-2' and C-6'), $130.99(\mathrm{C}-$ $3^{\prime}$ and C-5'), 134.73 (C-1'), 146.24 (C-4'), 129.93 (C-1"), 102.91 (C-2" and C-6"), 151.04 (C-3" and C-5"), 139.29 (C-4"), $21.91\left(-\mathrm{CH}_{3}, \mathrm{C}\right.$ of isobutyl group at C-4"), 29.34 (-CH-,C of isobutyl group at $\mathrm{C}-4 "), 45.56\left(-\mathrm{CH}_{2}-, \mathrm{C}\right.$ of isobutyl group at $\left.\mathrm{C}-4 "\right), 56.71\left(-\mathrm{OCH}_{3} \mathrm{C}\right.$ at $\mathrm{C}-3 ", \mathrm{C}-4$ " and C-5"); Anal. Calcd for: $\mathrm{C}_{20} \mathrm{H}_{22} \mathrm{O}_{2}$ : C, 74.55; H, 7.39; Found: C, 74.56; H, 7.43.

2.2.16. (E)-1-(4'-isobutylphenyl)-3-(2"-pyridinyl)-2-propen-1-one (A15): Yield 76\%; m.p. 132-134 ${ }^{\circ} \mathrm{C}$; IR $\left(\mathrm{KBr}, \mathrm{cm}^{-1}\right): 1651(\mathrm{C}=\mathrm{O}), 1581(\mathrm{C}=\mathrm{N}), 1604(\mathrm{C}=\mathrm{C}$ of $\mathrm{Ar}), 1505(\mathrm{CH}=\mathrm{CH})$, 1368 (C-N), 3006 (Ar C-H), 2799 (Alkyl C-H); ${ }^{1} \mathbf{H}$ NMR (400 MHz, CDCl $\left.3, \mathrm{ppm}\right): \delta 7.15$ $(1 \mathrm{H}, \mathrm{d}, J=17 \mathrm{~Hz},-\mathrm{CO}-\mathrm{CH}=), 7.51(1 \mathrm{H}, \mathrm{d}, J=17 \mathrm{~Hz},=\mathrm{CH}-\mathrm{Ar}), 6.32-8.41(8 \mathrm{H}, \mathrm{Ar}-\mathrm{H}), 1.91$ 
$\left(6 \mathrm{H}, \mathrm{d}, J=8 \mathrm{~Hz},-\left(\mathrm{CH}_{3}\right) 2\right), 1.89-2.09(1 \mathrm{H}, \mathrm{m},-\mathrm{CH}-), 2.33\left(2 \mathrm{H}, \mathrm{d}, J=8 \mathrm{~Hz},-\mathrm{CH}_{2}-\right) ;{ }^{13} \mathbf{C} \mathbf{N M R}$ (400 MHz, $\left.\mathrm{CDCl}_{3}, \mathrm{ppm}\right): \delta 189.70(\mathrm{C}-1), 127.73$ (C-2), 140.32 (C-3), 128.39 (C-2' and C-6'), 129.05 (C-3' and C-5'), 134.94 (C-1'), 147.11 (C-4'), 155.75 (C-2"), 122.02 (C-3"), 137.39 (C4"), 123.09 (C-5"), 149.16 (C-5"), 22.53 (-CH3, C of isobutyl group at $\mathrm{C}-4 "), 29.88$ (-CH-, C of isobutyl group at $\mathrm{C}-4 "), 45.99\left(-\mathrm{CH}_{2-}, \mathrm{C}\right.$ of isobutyl group at $\left.\mathrm{C}-4 "\right)$; Anal. Calcd for: $\mathrm{C}_{18} \mathrm{H}_{19} \mathrm{NO}$ : C, 81.47; H, 7.22; N, 5.28; Found: C, 81.51; H, 7.25; N, 5.33.

2.2.17. 1-(4'-isobutylphenyl)-3-(3"-pyridinyl)-2-propen-1-one (A16): Yield 86\%; m.p. 143$145^{\circ} \mathrm{C}$; IR $\left(\mathrm{KBr}, \mathrm{cm}^{-1}\right): 1645(\mathrm{C}=\mathrm{O}), 1590(\mathrm{C}=\mathrm{N}), 1603(\mathrm{C}=\mathrm{C}$ of $\mathrm{Ar}), 1502(\mathrm{CH}=\mathrm{CH}), 1370$ (C-N), 3098 (Ar C-H), 2937 (Alkyl C-H); ${ }^{1} \mathbf{H}$ NMR (400 MHz, CDCl3, ppm): $\delta 7.17(1 \mathrm{H}, \mathrm{d}$, $J=17 \mathrm{~Hz},-\mathrm{CO}-\mathrm{CH}=), 7.55(1 \mathrm{H}, \mathrm{d}, J=17 \mathrm{~Hz},=\mathrm{CH}-\mathrm{Ar}), 6.23-8.15(8 \mathrm{H}, \mathrm{Ar}-\mathrm{H}), 0.99(6 \mathrm{H}, \mathrm{d}, J$ $\left.=8 \mathrm{~Hz},-\left(\mathrm{CH}_{3}\right)_{2}\right), 1.90-2.13(1 \mathrm{H}, \mathrm{m},-\mathrm{CH}-), 2.59\left(2 \mathrm{H}, \mathrm{d}, J=8 \mathrm{~Hz},-\mathrm{CH}_{2}-\right) ;{ }^{13} \mathbf{C}$ NMR $(400$ $\left.\mathrm{MHz}, \mathrm{CDCl}_{3}, \mathrm{ppm}\right): \delta 188.20(\mathrm{C}-1), 127.31$ (C-2), 143.32 (C-3), 127.91 (C-2' and C-6'), 129.59 (C-3' and C-5'), 134.77 (C-1'), 146.52 (C-4'), 151.25 (C-2"), 132.26 (C-3"), 133.53 (C4"), 123.85 (C-5"), 149.99 (C-5"), 22.11 (-CH3, C of isobutyl group at C-4"), 29.59 (-CH-, C of isobutyl group at $\mathrm{C}-4 "), 45.12\left(-\mathrm{CH}_{2}-, \mathrm{C}\right.$ of isobutyl group at $\left.\mathrm{C}-4 "\right)$; Anal. Calcd for: $\mathrm{C}_{18} \mathrm{H}_{19} \mathrm{NO}$ : C, 81.47; H, 7.22; N, 5.28; Found: C, 81.51; H, 7.25; N, 5.33.

2.2.18. (E)-1-(4'-isobutylphenyl)-3-(4"-pyridinyl)-2-propen-1-one (A17): Yield 89\%; m.p. 165-167 ${ }^{\circ} \mathrm{C}$; IR $\left(\mathrm{KBr}, \mathrm{cm}^{-1}\right): 1650(\mathrm{C}=\mathrm{O}), 1581(\mathrm{C}=\mathrm{N}), 1605(\mathrm{C}=\mathrm{C}$ of $\mathrm{Ar}), 1505(\mathrm{CH}=\mathrm{CH})$, $1373(\mathrm{C}-\mathrm{N}), 3101$ (Ar C-H), 2811 (Alkyl C-H); ${ }^{1} \mathbf{H}$ NMR (400 MHz, CDCl $\left.3, \mathrm{ppm}\right): \delta 7.26$ $(1 \mathrm{H}, \mathrm{d}, J=17 \mathrm{~Hz},-\mathrm{CO}-\mathrm{CH}=), 7.61(1 \mathrm{H}, \mathrm{d}, J=17 \mathrm{~Hz},=\mathrm{CH}-\mathrm{Ar}), 6.21-8.59(8 \mathrm{H}, \mathrm{Ar}-\mathrm{H}), 0.93$ $\left(6 \mathrm{H}, \mathrm{d}, J=8 \mathrm{~Hz},-\left(\mathrm{CH}_{3}\right)_{2}\right), 2.12-2.17(1 \mathrm{H}, \mathrm{m},-\mathrm{CH}-), 2.62\left(2 \mathrm{H}, \mathrm{d}, J=8 \mathrm{~Hz},-\mathrm{CH}_{2}-\right) ;{ }^{13} \mathbf{C} \mathbf{~ N M R}$ (400 MHz, $\left.\mathrm{CDCl}_{3}, \mathrm{ppm}\right): \delta 188.59$ (C-1), 127.77 (C-2), 143.91 (C-3), 128.26 (C-2' and C-6'), 128.88 (C-3' and C-5'), 134.96 (C-1'), 146.97 (C-4'), 149.35 (C-2"), 121.75 (C-3"), 144.31 (C4"), 120.92 (C-5"), 149.97 (C-5"), 22.11 (-CH3, C of isobutyl group at C-4"), 29.59 (-CH-, C of isobutyl group at $\mathrm{C}-4 "), 45.12\left(-\mathrm{CH}_{2}-, \mathrm{C}\right.$ of isobutyl group at $\left.\mathrm{C}-4 "\right)$; Anal. Calcd for: $\mathrm{C}_{18} \mathrm{H}_{19} \mathrm{NO}$ : C, 81.47; H, 7.22; N, 5.28; Found: C, 81.51; H, 7.25; N, 5.33.

2.2.19. (E)-1-(4'-isobutylphenyl)-3-(2"-pyrrolyl)-2-propen-1-one (A18): Yield 82\%; m.p. 189-191 ${ }^{\circ} \mathrm{C}$; IR $\left(\mathrm{KBr}, \mathrm{cm}^{-1}\right): 1652(\mathrm{C}=\mathrm{O}), 1588(\mathrm{C}=\mathrm{N}), 1605(\mathrm{C}=\mathrm{C}$ of $\mathrm{Ar}), 1506(\mathrm{CH}=\mathrm{CH})$, 1375 (C-N), 3121 (Ar C-H), 2935 (Alkyl C-H); ${ }^{1} \mathbf{H}$ NMR (400 MHz, $\left.\mathrm{CDCl}_{3}, \mathrm{ppm}\right): \delta 5.10$ $(1 \mathrm{H}, \mathrm{s},-\mathrm{NH}), 7.24(1 \mathrm{H}, \mathrm{d}, J=17 \mathrm{~Hz},-\mathrm{CO}-\mathrm{CH}=), 7.60(1 \mathrm{H}, \mathrm{d}, J=17 \mathrm{~Hz},=\mathrm{CH}-\mathrm{Ar}), 6.94-7.72$ $(7 \mathrm{H}, \mathrm{Ar}-\mathrm{H}), 0.95\left(6 \mathrm{H}, \mathrm{d}, J=8 \mathrm{~Hz},-\left(\mathrm{CH}_{3}\right)_{2}\right), 1.85-2.07(1 \mathrm{H}, \mathrm{m},-\mathrm{CH}-), 2.55(2 \mathrm{H}, \mathrm{d}, J=8 \mathrm{~Hz},-$ $\left.\mathrm{CH}_{2-}\right) ;{ }^{13} \mathrm{C}$ NMR (400 MHz, $\left.\mathrm{CDCl}_{3}, \mathrm{ppm}\right): \delta 187.51$ (C-1), 126.23 (C-2), 132.74 (C-3), 129.17 (C-2' and C-6'), 129.88 (C-3' and C-5'), 134.61 (C-1'), 146.97 (C-4'), 129.51 (C-2"), 112.56 (C-3"), 108.26 (C-4"), 119.39 (C-5"), $23.12\left(-\mathrm{CH}_{3}, \mathrm{C}\right.$ of isobutyl group at C-4"), 30.63 (-CH-, C of isobutyl group at C-4"), 47.99 (-CH2-, C of isobutyl group at C-4"); Anal. Calcd for: $\mathrm{C}_{17} \mathrm{H}_{19} \mathrm{NO}$ : C, 80.60; H, 7.56; N, 5.53; Found: C, 80.64; H, 7.59; N, 5.54.

2.2.20. (E)-1-(4'-isobutylphenyl)-3-(2"-thienyl)-2-propen-1-one (A19): Yield 86\%; m.p. 179-181 ${ }^{\circ} \mathrm{C}$; IR $\left(\mathrm{KBr}, \mathrm{cm}^{-1}\right): 1655(\mathrm{C}=\mathrm{O}), 1610(\mathrm{C}=\mathrm{C}$ of $\mathrm{Ar}), 1505(\mathrm{CH}=\mathrm{CH}), 624(\mathrm{C}-\mathrm{S})$, 3119 (Ar C-H), 2954 (Alkyl C-H); ${ }^{1} \mathbf{H}$ NMR (400 MHz, CDCl $\left.3, \mathrm{ppm}\right): \delta 7.34(1 \mathrm{H}, \mathrm{d}, J=17$ $\mathrm{Hz},-\mathrm{CO}-\mathrm{CH}=), 7.82(1 \mathrm{H}, \mathrm{d}, J=17 \mathrm{~Hz},=\mathrm{CH}-\mathrm{Ar}), 6.85-8.30(7 \mathrm{H}, \mathrm{Ar}-\mathrm{H}), 0.85(6 \mathrm{H}, \mathrm{d}, J=8$ $\left.\mathrm{Hz},-\left(\mathrm{CH}_{3}\right)_{2}\right), 1.71-2.09(1 \mathrm{H}, \mathrm{m},-\mathrm{CH}-), 2.99\left(2 \mathrm{H}, \mathrm{d}, J=8 \mathrm{~Hz},-\mathrm{CH}_{2}-\right) ;{ }^{13} \mathbf{C}$ NMR $(400 \mathrm{MHz}$, $\left.\mathrm{CDCl}_{3}, \mathrm{ppm}\right): \delta 189.98(\mathrm{C}-1), 127.95(\mathrm{C}-2), 134.26(\mathrm{C}-3), 130.76(\mathrm{C}-2$ ' and C-6'), $129.76(\mathrm{C}-$ $3^{\prime}$ and C-5'), 135.84 (C-1'), 147.38 (C-4'), 138.85 (C-2"), 128.21 (C-3"), 129.15 (C-4"), 130.19 $(\mathrm{C}-5 "), 22.91\left(-\mathrm{CH}_{3}, \mathrm{C}\right.$ of isobutyl group at $\left.\mathrm{C}-4 "\right), 30.11$ (-CH-, $\mathrm{C}$ of isobutyl group at $\left.\mathrm{C}-4 "\right)$, $47.12\left(-\mathrm{CH}_{2}-, \mathrm{C}\right.$ of isobutyl group at $\left.\mathrm{C}-4 "\right)$; Anal. Calcd for: $\mathrm{C}_{17} \mathrm{H}_{18} \mathrm{SO}$ : C, 75.51; H, 6.71; Found: C, 75.55; H, 6.73. 
2.2.21. (E)-1-(4'-isobutylphenyl)-3-(5"-bromofuran-2"-yl)-2-propen-1-one (A20): Yield 85\%; m.p. $149-151{ }^{\circ} \mathrm{C}$; IR $\left(\mathrm{KBr}, \mathrm{cm}^{-1}\right): 1652(\mathrm{C}=\mathrm{O}), 1585(\mathrm{C}=\mathrm{C}$ of $\mathrm{Ar}), 1503(\mathrm{CH}=\mathrm{CH})$, 2959 (Ar C-H), 2713 (Alkyl C-H); ${ }^{1} \mathbf{H}$ NMR (400 MHz, CDCl $\left.3, \mathrm{ppm}\right): \delta 7.19(1 \mathrm{H}, \mathrm{d}, J=17$ $\mathrm{Hz},-\mathrm{CO}-\mathrm{CH}=), 7.79(1 \mathrm{H}, \mathrm{d}, J=17 \mathrm{~Hz},=\mathrm{CH}-\mathrm{Ar}), 6.89-7.85(7 \mathrm{H}, \mathrm{Ar}-\mathrm{H}), 1.01(6 \mathrm{H}, \mathrm{d}, J=8$ $\left.\mathrm{Hz},-\left(\mathrm{CH}_{3}\right)_{2}\right), 2.05-2.22(1 \mathrm{H}, \mathrm{m},-\mathrm{CH}-), 2.62\left(2 \mathrm{H}, \mathrm{d}, J=8 \mathrm{~Hz},-\mathrm{CH}_{2}-\right) ;{ }^{13} \mathbf{C}$ NMR $(400 \mathrm{MHz}$, $\left.\mathrm{CDCl}_{3}, \mathrm{ppm}\right): \delta 189.88(\mathrm{C}-1), 127.58(\mathrm{C}-2), 131.43(\mathrm{C}-3), 130.21\left(\mathrm{C}-2{ }^{\prime}\right.$ and C-6'), $128.95(\mathrm{C}-$ $3^{\prime}$ and C-5'), 135.13 (C-1'), 146.88 (C-4'), 154.81 (C-2"), 114.38 (C-3"), 114.67 (C-4"), 123.12 $(\mathrm{C}-5 "), 22.65\left(-\mathrm{CH}_{3}, \mathrm{C}\right.$ of isobutyl group at $\left.\mathrm{C}-4 "\right), 29.81$ (-CH-, $\mathrm{C}$ of isobutyl group at $\left.\mathrm{C}-4 "\right)$, $46.66\left(-\mathrm{CH}_{2-}, \mathrm{C}\right.$ of isobutyl group at $\left.\mathrm{C}-4\right)$; Anal. Calcd for: $\mathrm{C}_{17} \mathrm{H}_{17} \mathrm{BrO}_{2}$ : C, 61.28; $\mathrm{H}, 5.14$; Found: C, 61.33; H, 5.17.

\subsection{In vitro cytotoxicity assays}

Compounds (A1 to A20) were evaluated for cytotoxic activity against HT-29, MCF-7 and DU-145 cell lines by means of MTT [3-(4,5-dimethylthiazo-2-yl)-2,5-diphenyltetrazoliumbromide] cell proliferation assay (Mosmann 1983). This is a colorimetric assay that measures the reduction of yellow MTT by mitochondrial reductase to an insoluble, dark purple coloured formazan. The cells are then treated with DMSO to solubilize formazan which is measured spectrophotometrically at $570 \mathrm{~nm}$. Since reduction of MTT can only occur in metabolically active cells, the level of activity is a measure of the viability of the cells [28, 29].

HT-29 and DU-145 cell lines were grown as adherent in DMEM media, whereas MCF-7 was grown in MEM media supplemented with $10 \%$ fetal bovine serum. The cultures were maintained in a humidified atmosphere with $5 \% \mathrm{CO}_{2}$. Stock solutions of test compounds (A1 to A20) were prepared $(10 \mathrm{mg} / \mathrm{mL})$ in DMSO and from them various dilutions were made with sterile water to get the final drug concentrations of $10,50,100$ and $200 \mathrm{mg} / \mathrm{mL}$.

Cell lines were seeded in 96 well plates at a concentration of $1 \times 10^{4} /$ well and incubated for $24 \mathrm{~h}$ at $37{ }^{\circ} \mathrm{C}$, and then the medium was replaced with fresh media containing different dilutions of the test compounds and incubated for additional $48 \mathrm{~h}$ at $37{ }^{\circ} \mathrm{C}$ in DMEM/MEM with $10 \%$ FBS medium. Subsequently the medium was replaced with $90 \mu \mathrm{L}$ of fresh DMEM without FB. Above wells were treated with $10 \mu \mathrm{L}$ of MTT reagent $(5 \mathrm{mg} / \mathrm{mL}$ of stock solution in DMEM without FBS) and incubated at $37{ }^{\circ} \mathrm{C}$ for 3-4 h. The formed blue formazan crystals were dissolved in $200 \mu \mathrm{L}$ of DMSO. The absorbance at $570 \mathrm{~nm}$ was measured on a spectrophotometer. Anticancer agent methotrexate (Mtx) was used as positive control. Assay was performed in triplicate for three independent determinations. The cytotoxicity was expressed as $\mathrm{IC}_{50}(\mu \mathrm{g} / \mathrm{mL})$.

\subsection{Computational evaluation}

A set of 20 synthesized chalcones were selected to build the pharmacophore using PHASETM $\mathrm{V}$ 3.1 (Schrödinger LLC, Portland, Oregon, USA; http://www.schrodinger.com/). The $\mathrm{IC}_{50}$ values emerged out of the cytotoxicity studies on the three cancer cell lines HT-29, MCF-7 and DU145 were used to perform the required study with PHASETM. The 3D-structure of the ligands were built and minimized with ChemDraw Ultra ${ }^{\mathrm{TM}}$ v 10.0 (CambridgeSoft Corporation, Cambridge, MA, USA; http://www.cambridgesoft.com/) and were incorporated into PHASETM and then cleaned by the PHASE's LipPreg ${ }^{\mathrm{TM}}$ module. The set of new chalcones were divided 
into active or inactive according to their $-\log 10$ ( $\left.\mathrm{IC}_{50}\right)$ values. Tree-based partitioning technique was applied for the identification of pharmacophores that are common to a set of active compounds which have a specific number of pharmacophore sites. Thus in this study, the total number of required active compounds and the number of pharmacophores were reduced to 4. By following the above process, we obtained a list of different variants for different pharmacophore models which were the result of the combinations of five pharmacophore features including, one H-bond acceptor (A), two hydrophobic groups $(\mathrm{H})$ and aromatic rings $(\mathrm{R})$ respectively. The hypothesis identified by Phase was scored according to how the active ligands superimpose on features associated with that hypothesis.

\section{Results and Discussion}

\subsection{Chemistry.}

The designed novel target isobutylchalcones were synthesized by conventional base-catalyzed Claisen-Schmidt condensation of 1-(4-isobutylphenyl)ethanone and aromatic or heteroaromatic aldehyde as illustrated in Scheme 1. Most of the compounds were pure as evidenced by their TLC profiles and the impure compounds were purified by recrystallization using ethanol. Structures of the purified compounds (A1-A20) were explicitly unravelled on the basis of spectroscopic data (IR, ${ }^{1} \mathrm{H}$ NMR, ${ }^{13} \mathrm{C}$ NMR) and the results were consistent with the proposed structures of the compounds. Two intense characteristic IR absorption bands in the range 1645$1660 \mathrm{~cm}^{-1}(-\mathrm{C}=\mathrm{O})$ and $1450-1520 \mathrm{~cm}^{-1}(-\mathrm{C}=\mathrm{C}-)$ respectively confirmed the formation of chalcone bridge. Additional $-\mathrm{C}=\mathrm{C}$ - and $-\mathrm{C}-\mathrm{H}$ stretching bands in the range $1580-1610 \mathrm{~cm}^{-1}$ and $3010-3150 \mathrm{~cm}^{-1}$ had confirmed the presence of aromatic rings. A characteristic band appearing in the range of $2750-2850 \mathrm{~cm}^{-1}$ corresponds to the alkyl $-\mathrm{C}-\mathrm{H}$ stretching of the isobutyl group. The ${ }^{1} \mathrm{H}$ NMR spectrum of these compounds showed the characteristic resonance of - $\mathrm{CO}-\mathrm{CH}=$ $(\alpha-\mathrm{H})$ around $\delta$ 6.7-7.4 ppm and $\delta$ 7.3-7.8 $=\mathrm{CH}-\mathrm{Ar}(\beta-\mathrm{H})$ as doublets with coupling constant $(\boldsymbol{J}$ $=\mathbf{1 7} \mathrm{HZ}$ ) respectively confirming the trans $(E)$ geometry at the ethylenic double bond of the molecule. The peaks in between $\delta$ 6-8 accounts for the other aromatic protons. Further the doublet between $\delta 0.80-1.10$ integrated for the six protons of two methyl groups, multiplet around $\delta$ 1.60-2.20 integrated for one methine (methanetriyl) proton and a doublet between 2.30-2.80 integrated for two methylene protons of the isobutyl group. Other protons exhibited additional resonance signals typically present in each compound. ${ }^{13} \mathrm{C}$ NMR of compounds exhibited the diagnostic signals around $\delta$ 186-191 (C-1), 120-128 (C-2) and 131-142 (C-3). The composition of the synthesized compounds was confirmed by elemental analysis and the results were also in close agreement with those of the calculated values.

\subsection{In vitro cytotoxicity assays and structure activity relationships}

As noticeable from Table 1 ( $\mathrm{IC}_{50}$ in $\mu \mathrm{g} / \mathrm{ml}$ ), most of the compounds possess cytotoxic activity but less compared to the standard methotrexate. All the compounds were active against DU-145 and some being inactive against the other two cell lines. Among the three cell lines the compounds were more active against DU-145 compared to HT-29 and MCF-7. 2",4"difluorophenyl chalcone A6, exhibited maximum activity against all the cell lines with an $\mathrm{IC}_{50}$ $(\mu \mathrm{g} / \mathrm{ml})$ values of 42 (HT-29), 38 (MCF-7) and 18 (DU-145) whereas A3 containing 2",4"- 
dichlorophenyl moiety was next in potency to A6 against HT-29 (67 $\mu \mathrm{g} / \mathrm{ml})$, MCF-7 (58 $\mu \mathrm{g} / \mathrm{ml})$ and DU-145 $(23 \mu \mathrm{g} / \mathrm{ml})$ respectively. Chalcones A8, A14, and A19 containing 3"bromophenyl, 3",4",5"-trimethoxyphenyl and 2"-thienyl respectively were inactive against both HT-29 and MCF-7 while A2, A7 and A20 with 4"-methylphenyl, 4"dimethylaminophenyl and 5"-bromofuran-2"-yl were inactive only against MCF-7.

Against HT-29 chalcones with electron releasing groups 4"-fluorophenyl (A5), 4"chlorophenyl (A1), 4"-nitrophenyl (A11) were active with $\mathrm{IC}_{50}$ values 68, 76 and $85 \mu \mathrm{g} / \mathrm{ml}$ respectively subsequent to $\mathbf{A 3}$ and A6. Intriguingly compounds A2 with electron releasing 4"methylphenyl and A17 with heteroaryl 4"-pyridinyl were also active with IC 50 of 90 and 93 but less than that of the substituents with electron withdrawing groups. It suggests that electron withdrawing group at 4"-position was more essential for activity than electron releasing groups and heteroaryl scaffold. Substitution with electron withdrawing groups only at 2"- and 3"positions or with five membered heterocycles makes the compounds less active or inactive. Hence six membered aryl heteroaryl with more number of electron withdrawing groups can be synthesized for further escalating the potency. The other compounds were active at concentrations higher than $100 \mu \mathrm{g} / \mathrm{ml}$.

Interestingly, against MCF-7 chalcone A17 with 4"-pyridinyl system was more active than A5 with 4"-fluorophenyl and A11 with 4"-nitrophenyl. Nearly equal potencies of the three compounds again represented the importance of electron withdrawing group at 4"-position and six membered heteroaryl scaffolds for activity.

Table 1. Cytotoxicity of compounds A1-A20 against different cell lines in comparison to methotrexate ( $\mathrm{IC}_{50}$ in $\mu \mathrm{g} / \mathrm{ml}$ )

Compound


A5<smiles>CC(C)Cc1ccc(C(=O)/C=C/c2ccc(F)cc2)cc1</smiles>

A6<smiles>CC(C)Cc1ccc(C(=O)/C=C/c2ccc(F)cc2F)cc1</smiles>

A7<smiles>CC(C)Cc1ccc(C(=O)/C=C/c2ccc(N(C)C)cc2)cc1</smiles><smiles>CC(C)Cc1ccc(C(=O)/C=C/c2cccc(Br)c2)cc1</smiles>

A8

A9<smiles>CC(C)Cc1ccc(C(=O)/C=C/c2ccc(O)cc2)cc1</smiles>

A10<smiles>CC(C)Cc1ccc(C(=O)/C=C/c2cccc(O)c2)cc1</smiles>

A11<smiles>CC(C)Cc1ccc(C(=O)/C=C/c2ccc([N+](=O)[O-])cc2)cc1</smiles>

A12<smiles>COc1ccc(/C=C/C(=O)c2ccc(CC(C)C)cc2)cc1</smiles>

$68 \pm 2 \quad 89 \pm 1 \quad 43 \pm 2$

$42 \pm 2 \quad 38 \pm 1 \quad 18 \pm 1$

$110 \pm 2 \quad \mathrm{NA} \quad 101 \pm 2$

NA NA $155 \pm 2$

$146 \pm 2 \quad 167 \pm 2 \quad 120 \pm 1$

$164 \pm 2 \quad 182 \pm 2 \quad 176 \pm 2$

$85 \pm 2 \quad 92 \pm 2 \quad 68 \pm 3$

$124 \pm 2 \quad 133 \pm 1 \quad 78 \pm 2$ 
A13<smiles>COc1ccc(/C=C/C(=O)c2ccc(CC(C)C)cc2)cc1OC</smiles>

$146 \pm 2 \quad 153 \pm 2 \quad 82 \pm 2$

A14<smiles>COc1cc(/C=C/C(=O)c2ccc(CC(C)C)cc2)cc(OC)c1OC</smiles>

NA NA

$174 \pm 2$

A15<smiles>CC(C)Cc1ccc(C(=O)/C=C/c2ccccn2)cc1</smiles>

$120 \pm 1 \quad 172 \pm 2 \quad 105 \pm 2$

A16<smiles>CC(C)Cc1ccc(C(=O)/C=C/c2cccnc2)cc1</smiles>

$132 \pm 1 \quad 117 \pm 2 \quad 105 \pm 2$

A17<smiles>CC(C)Cc1ccc(C(=O)/C=C/c2ccncc2)cc1</smiles>

$93 \pm 2 \quad 88 \pm 1 \quad 74 \pm 2$

A18<smiles>CC(C)Cc1ccc(C(=O)/C=C/c2ccc[nH]2)cc1</smiles>

NA $\quad 148 \pm 2 \quad 107 \pm 2$

A19<smiles>CC(C)Cc1ccc(C(=O)/C=C/c2cccs2)cc1</smiles>

NA

NA $\quad 123 \pm 2$

A20<smiles>CC(C)Cc1ccc(C(=O)/C=C/c2ccc(Br)o2)cc1</smiles>
$190 \pm 2 \quad$ NA $\quad 116 \pm 1$

\section{NA $=$ No activity}

DU-145 cell line was most susceptibile of the three cell lines. In this case the chalcones A2 with 4"-methyl, A12 with 4"-methoxyphenyl and A13 with 3",4"- methoxyphenyl possessed potencies below 100. It seems that for cytotoxic activity against DU-145 cell line 
chalcones with electron releasing/withdrawing/heteroaryl were important. Compounds with five membered heterocycles also possess some inhibitory activity.

In summary, for chalcones to be act as potential cytotoxic agents against the cell lines, it could be observed that chalcone bridge with isobutyl phenyl ring-A is essential and the structural requirements of ring-B (Figs. 3 and $\mathbf{4}$ ) are as follows.

a) HT-29: 6-membered aryl rings with 2",4"-di/4-mono EWGs or 6-membered heteroaryl.

b) MCF-7: 6-membered aryl rings with 2",4"-di/4-mono EWGs or 6-membered heteroaryl.

c) DU-145: (i) 6-membered aryl rings with EWGs at 2",4"- or 4"-positions.

(ii) 6-membered aryl rings with ERGs at 4" or 3" - and 4"-positions.

(iii) 6-membered heteroaryl rings.

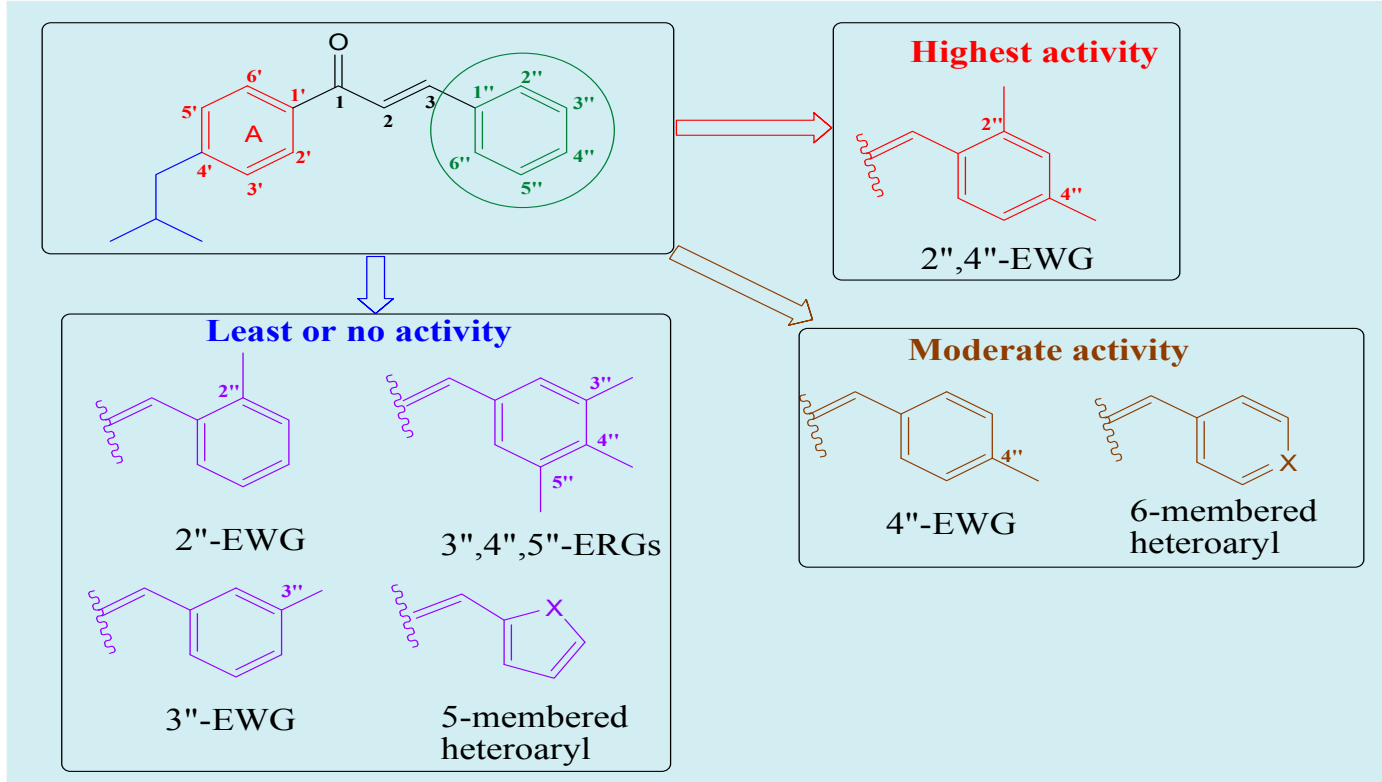

Figure 3. Structure activity relationships of chalcones against HT-29 and MCF-7; X=N or S $\mathrm{ERG}=$ Electron releasing groups; $\mathrm{EWG}=$ Electron withdrawing groups

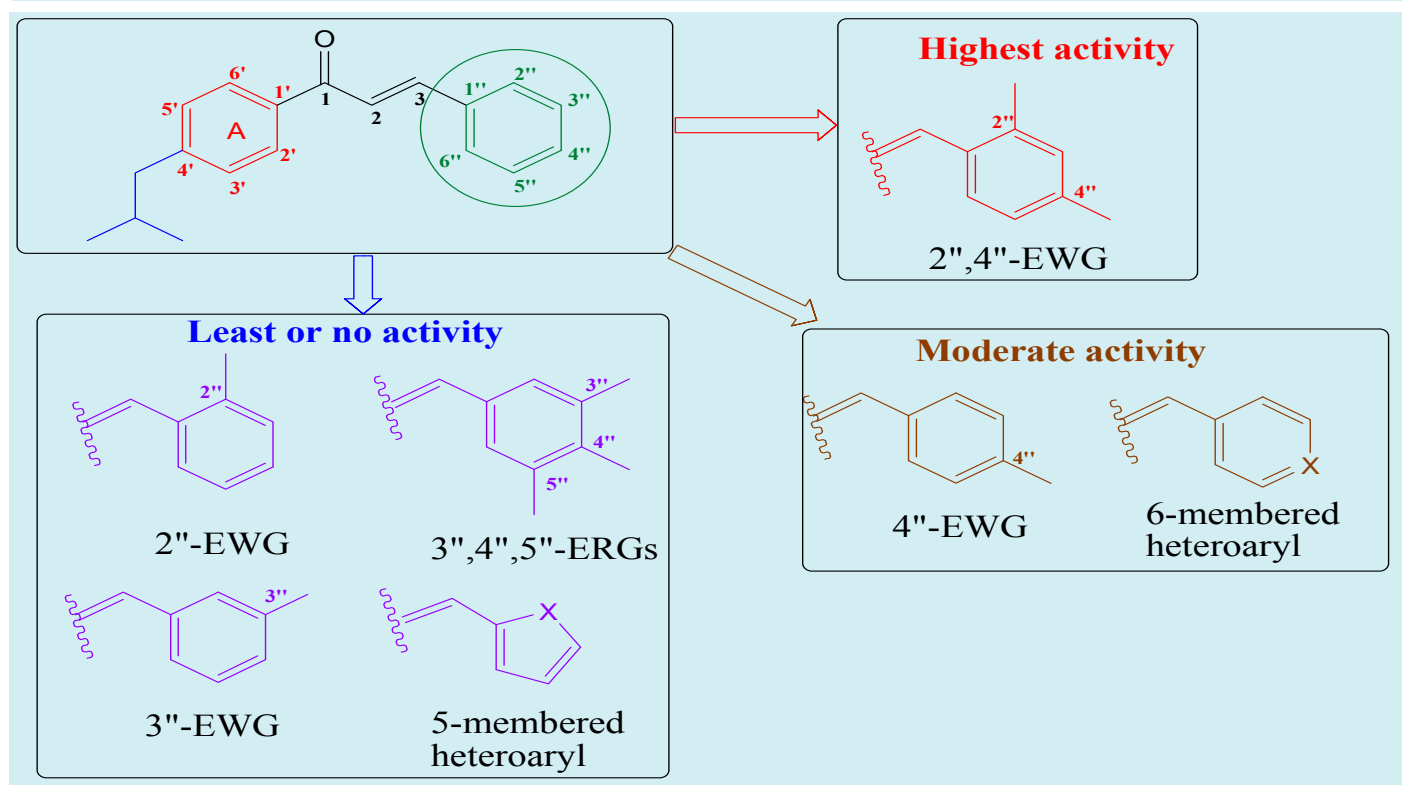

Figure 4. Structure activity relationships of chalcones against HT-29 and MCF-7; X=N or S $\mathrm{ERG}=$ Electron releasing groups; $\mathrm{EWG}=$ Electron withdrawing groups 


\subsection{Computational evaluation}

From the pharmacophore modelling results, it was able to identify a common pharmacophore with a five point model AHHRR (Fig. 5). The parameters of the five point model are presented in Table 2. Two pharmacophore hypotheses were chosen. The pharmacophore hypothesis-1, AHHRR.43* and hypothesis-2, AHHRR.25* that were selected belong to a box that had survived the partitioning process as characterized by five sites (i.e., the hypothesis contained one hydrogen bond acceptor (A), two hydrophobic groups $(\mathrm{H})$ and two aromatic rings $(\mathrm{R}))$ at a specific intersite distance and specific bond angles as shown in Tables 3, 4, 5 and 6 respectively. These hypotheses were selected on the basis of the active and the inactive compounds (i.e. the less active compounds), because the subsequent inactive compounds were used to penalize. Thus, we chose the hypothesis with the highest survival score after the penalization with the inactive compounds. Phase generated pharmacophore hypothesis-1 and 2 are shown in figures 6 and 8 . The pharmacophore hypothesis-1 was generated from the chalcone A6 (Fig. 7) having a fitness factor 3 and the IC 50 values $42 \pm 2,38 \pm 1,18 \pm 1$ on cell lines HT-29, MCF-7 and DU-145 respectively whereas the chalcone $\mathbf{A 3}$ was utilized to generate pharmacophore hypothesis-2 (Fig. 9) having fitness factor 3 and the $\mathrm{IC}_{50}$ values $67 \pm 2,58 \pm 1,23 \pm 1$ on cell lines HT-29, MCF-7 and DU-145 respectively. These results can be considered as moderate when compared with the standard methotrexate ( $\mathrm{IC}_{50}$ values $12 \pm 1,9 \pm 1,5 \pm 1$ on cell lines HT-29, MCF-7 and DU-145 respectively). The pharmacophore models are in correlation with the invitro activity data and clearly explained the importance of ring-A with 4'-isobutyl substituent and ring-B with electron withdrawing groups.

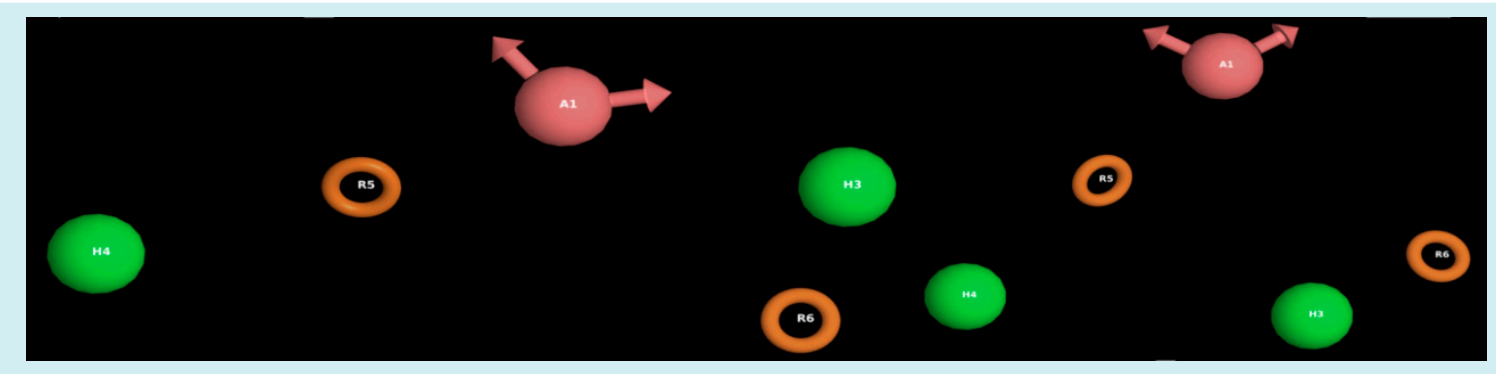

Figure 5. Common pharmacophore hypothesis generated using the set of all 20 chalcones illustrating hydrophobic groups (H, Green spheres), aromatic rings (R, Orange spheres) and hydrogen bond acceptor (A, Pink sphere).
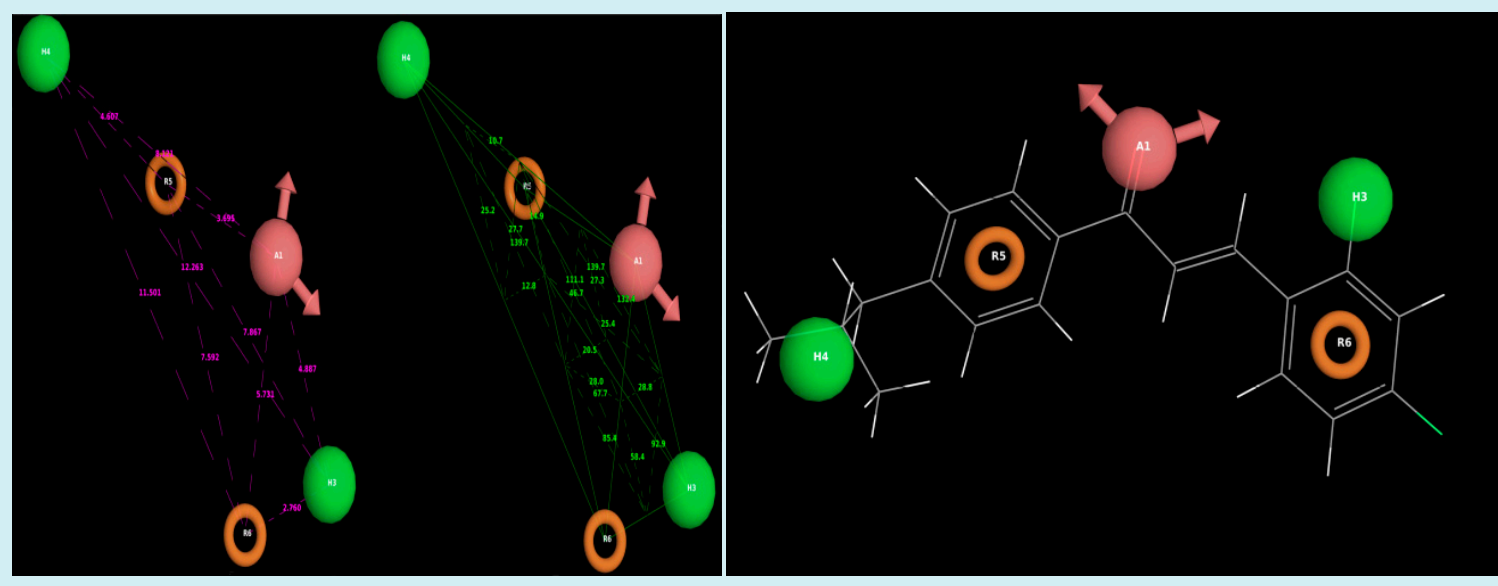

Figure 6. Phase generated pharmacophore hypothesis-1 AHHRR.43*and distance/angle between pharmacophoric sites.

Figure 7. Phase generated best pharmacophore hypothesis-1 AHHRR.43* aligned with molecule A6. 


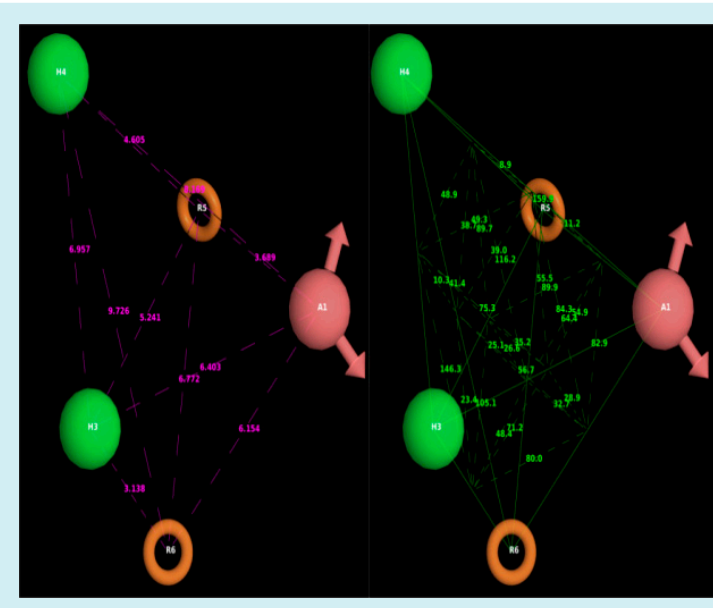

Figure 8. Phase generated pharmacophore hypothesis-2 AHHRR.25*and distance/angle between pharmacophoric sites. All distances are in Å unit.

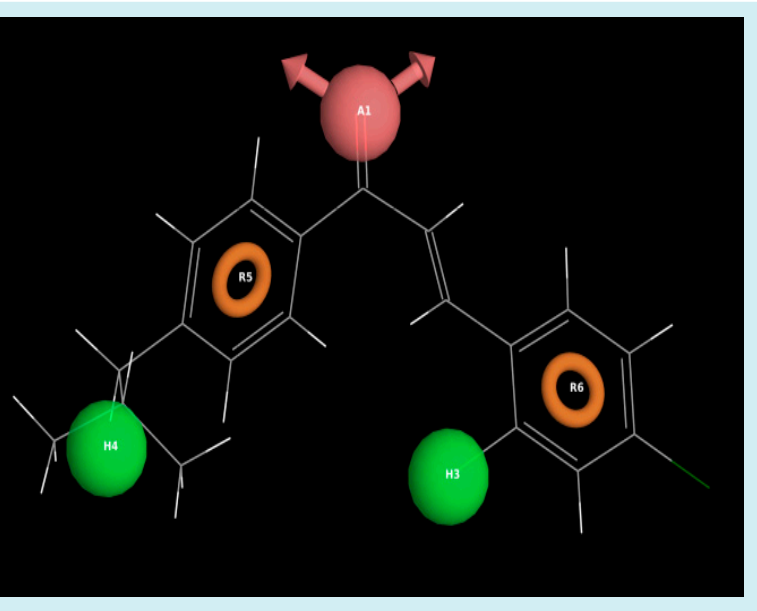

Figure 9. Phase generated best pharmacophore hypothesis-2 AHHRR.25* aligned with molecule A3.

Table 2. Parameters of the five featured pharmacophore

\begin{tabular}{|c|c|c|c|c|c|c|c|}
\hline S.No & ID & Survival & Site & Vector & Volume & Selectivity & Energy \\
\hline 1. & AHHRR.43* & $\mathbf{3 . 6 9 6}$ & $\mathbf{0 . 8 1}$ & $\mathbf{0 . 9 9 5}$ & $\mathbf{0 . 8 8 7}$ & $\mathbf{1 . 9 3}$ & $\mathbf{0 . 2 5}$ \\
\hline 2. & AHHRR.5 & 3.682 & 0.8 & 0.995 & 0.885 & 1.928 & 0.251 \\
\hline 3. & AHHRR.23 & 3.682 & 0.8 & 0.995 & 0.885 & 1.922 & 0.53 \\
\hline 4. & AHHRR.3 & 3.68 & 0.78 & 0.992 & 0.906 & 1.982 & 0.107 \\
\hline 5. & AHHRR.4 & 3.68 & 0.78 & 0.992 & 0.906 & 1.979 & 0.044 \\
\hline 6. & AHHRR.25* & $\mathbf{3 . 6 7 7}$ & $\mathbf{0 . 7 8}$ & $\mathbf{0 . 9 9 1}$ & $\mathbf{0 . 9 0 3}$ & $\mathbf{2 . 0 0 2}$ & $\mathbf{0 . 1 8}$ \\
\hline 7. & AHHRR.26 & 3.677 & 0.78 & 0.991 & 0.903 & 2 & 0.09 \\
\hline 8. & AHHRR.65 & 3.657 & 0.77 & 0.996 & 0.887 & 1.997 & 0.25 \\
\hline 9. & AHHRR.72 & 3.657 & 0.77 & 0.996 & 0.887 & 1.99 & 0.528 \\
\hline 10. & HHHRR.51 & 3.654 & 0.79 & 0.993 & 0.872 & 1.969 & 0.25 \\
\hline 11. & HHHRR.54 & 3.654 & 0.79 & 0.993 & 0.872 & 1.955 & 0.528 \\
\hline 12. & AHHHR.111 & 3.652 & 0.76 & 0.999 & 0.888 & 1.828 & 0.25 \\
\hline 13. & AHHHR.112 & 3.652 & 0.76 & 0.999 & 0.888 & 1.825 & 0.528 \\
\hline 14. & AHHHR.101 & 3.644 & 0.73 & 0.999 & 0.917 & 1.908 & 0 \\
\hline 15. & AHHHR.102 & 3.644 & 0.73 & 0.999 & 0.917 & 1.91 & 0 \\
\hline 16. & AHHHR.107 & 3.644 & 0.76 & 0.993 & 0.891 & 1.878 & 0.25 \\
\hline 17. & AHHHR.108 & 3.644 & 0.76 & 0.993 & 0.891 & 1.874 & 0.528 \\
\hline 18. & AHHHR.83 & 3.636 & 0.75 & 0.999 & 0.888 & 1.825 & 0.251 \\
\hline 19. & HHHRR.52 & 3.635 & 0.77 & 0.993 & 0.875 & 1.968 & 0.251 \\
\hline 20. & HHHRR.56 & 3.635 & 0.77 & 0.993 & 0.875 & 1.95 & 0.53 \\
\hline *selected pharmacophore hypothesis & & & \\
\hline
\end{tabular}




\section{Table 3. Distances between different sites of pharmacophore model AHHRR.43*}

\begin{tabular}{|c|c|c|c|}
\hline Entry & Site1 & Site2 & Distance \\
\hline AHHRR.43 & A1 & H3 & 4.887 \\
\hline AHHRR.43 & A1 & H4 & 8.121 \\
\hline AHHRR.43 & A1 & R5 & 3.695 \\
\hline AHHRR.43 & A1 & R6 & 5.731 \\
\hline AHHRR.43 & H3 & H4 & 12.263 \\
\hline AHHRR.43 & H3 & R5 & 7.867 \\
\hline AHHRR.43 & H3 & R6 & 2.760 \\
\hline AHHRR.43 & H4 & R5 & 4.607 \\
\hline AHHRR.43 & H4 & R6 & 11.501 \\
\hline AHHRR.43 & R5 & R6 & 7.592 \\
\hline
\end{tabular}

Table 4. Distances between different sites of pharmacophore model AHHRR.25*

\begin{tabular}{|c|c|c|c|}
\hline Entry & Site1 & Site2 & Distance \\
\hline AHHRR.25 & A1 & H3 & 6.403 \\
\hline AHHRR.25 & A1 & H4 & 8.169 \\
\hline AHHRR.25 & A1 & R5 & 3.689 \\
\hline AHHRR.25 & A1 & R6 & 6.154 \\
\hline AHHRR.25 & H3 & H4 & 6.957 \\
\hline AHHRR.25 & H3 & R5 & 5.241 \\
\hline AHHRR.25 & H3 & R6 & 3.138 \\
\hline AHHRR.25 & H4 & R5 & 4.605 \\
\hline AHHRR.25 & H4 & R6 & 9.726 \\
\hline AHHRR.25 & R5 & R6 & 6.772 \\
\hline
\end{tabular}

\section{Conclusions}

A series of twenty chalcones were prepared by simple Claisen-Schmidt condensation reaction of isobutylacetophenone with aromatic aldehydes containing electron releasing or withdrawing substituents on other aryl or heteroaryl rings (B) for comparing the in vitro cytotoxic activity. Among the compounds tested for cytotoxic activity the chalcone A6 with electron withdrawing 2",4"-difluorophenyl moiety was found to be most potent against all the three cancer cell lines. The compound A3 with 2",4"-dichlorophenyl moiety also possessed comparable cytotoxic potency. From the SAR studies it could be inferred that the chalcone bridge linked to 4'-isobutyphenyl ring and ring-B with electron withdrawing substituents in ortho and para positions are very much essential for cytotoxic activity. All the twenty chalcones were subjected to pharmacophore modeling using PHASE ${ }^{\mathrm{TM}}$ software. The computational results revealed the most potent nature of chalcones A6 having a 2,4difluorophenyl moiety and $\mathbf{A 3}$ having a 2,4-dichlorophenyl moiety against the tested cell lines. The pharmacophores generated from these two compounds by the two proposed hypotheses (as discussed under results) accounts for the said cytotoxicity and further these models can be used as a reference to identify features required for newly synthesized chalcones for their cytotoxicity. 
Table 5. Angles between different sites of model AHHRR.43*.

\begin{tabular}{|c|c|c|c|c|}
\hline Entry & Site1 & Site2 & Site3 & Angle \\
\hline AHHRR.43 & H3 & A1 & $\mathrm{H} 4$ & 139.7 \\
\hline AHHRR.43 & $\mathrm{H} 3$ & A1 & $\mathrm{R} 5$ & 132.4 \\
\hline AHHRR.43 & H3 & A1 & R6 & 28.8 \\
\hline AHHRR.43 & $\mathrm{H} 4$ & A1 & R5 & 13.4 \\
\hline AHHRR.43 & $\mathrm{H} 4$ & A1 & R6 & 111.1 \\
\hline AHHRR.43 & R5 & A1 & R6 & 105.2 \\
\hline AHHRR.43 & A1 & H3 & $\mathrm{H} 4$ & 25.4 \\
\hline AHHRR.43 & A1 & $\mathrm{H} 3$ & $\mathrm{R} 5$ & 20.3 \\
\hline AHHRR.43 & A1 & $\mathrm{H} 3$ & R6 & 92.9 \\
\hline AHHRR.43 & $\mathrm{H} 4$ & H3 & R5 & 8.1 \\
\hline AHHRR.43 & $\mathrm{H} 4$ & H3 & R6 & 67.7 \\
\hline AHHRR.43 & R5 & H3 & R6 & 74.1 \\
\hline AHHRR.43 & A1 & $\mathrm{H} 4$ & H3 & 14.9 \\
\hline AHHRR.43 & A1 & $\mathrm{H} 4$ & R5 & 10.7 \\
\hline AHHRR.43 & A1 & H4 & R6 & 27.7 \\
\hline AHHRR.43 & H3 & $\mathrm{H} 4$ & R5 & 13.8 \\
\hline AHHRR.43 & H3 & $\mathrm{H} 4$ & R6 & 12.8 \\
\hline AHHRR.43 & R5 & $\mathrm{H} 4$ & R6 & 25.2 \\
\hline AHHRR.43 & A1 & R5 & H3 & 27.3 \\
\hline AHHRR.43 & A1 & R5 & $\mathrm{H} 4$ & 155.8 \\
\hline AHHRR.43 & A1 & R5 & R6 & 46.7 \\
\hline AHHRR.43 & H3 & R5 & H4 & 158.1 \\
\hline AHHRR.43 & H3 & R5 & R6 & 20.5 \\
\hline AHHRR.43 & $\mathrm{H} 4$ & R5 & R6 & 139.7 \\
\hline AHHRR.43 & A1 & R6 & $\mathrm{H} 3$ & 58.4 \\
\hline AHHRR.43 & A1 & R6 & $\mathrm{H} 4$ & 41.2 \\
\hline AHHRR.43 & A1 & R6 & R5 & 28.0 \\
\hline AHHRR.43 & $\mathrm{H} 3$ & R6 & $\mathrm{H} 4$ & 99.5 \\
\hline AHHRR.43 & $\mathrm{H} 3$ & R6 & R5 & 85.4 \\
\hline AHHRR.43 & $\mathrm{H} 4$ & R6 & R5 & 15.0 \\
\hline
\end{tabular}

\section{Conflict of Interests}

There is no conflict of interests.

\section{Acknowledgements}

The authors like to acknowledge Ministry of Minority Affairs, Indian Government, for providing UGC- Maulana Azad National Fellowship. sites of model AHHRR.25*.

\begin{tabular}{|c|c|c|c|c|}
\hline Entry & Site1 & Site2 & Site3 & Angle \\
\hline AHHRR.25 & H3 & A1 & H4 & 55.5 \\
\hline AHHRR.25 & H3 & A1 & R5 & 54.9 \\
\hline AHHRR.25 & H3 & A1 & R6 & 28.9 \\
\hline AHHRR.25 & H4 & A1 & R5 & 11.2 \\
\hline AHHRR.25 & H4 & A1 & R6 & 84.3 \\
\hline AHHRR.25 & R5 & A1 & R6 & 82.9 \\
\hline AHHRR.25 & A1 & H3 & H4 & 75.3 \\
\hline AHHRR.25 & A1 & H3 & R5 & 35.2 \\
\hline AHHRR.25 & A1 & H3 & R6 & 71.2 \\
\hline AHHRR.25 & H4 & H3 & R5 & 41.4 \\
\hline AHHRR.25 & H4 & H3 & R6 & 146.3 \\
\hline AHHRR.25 & R5 & H3 & R6 & 105.1 \\
\hline AHHRR.25 & A1 & H4 & H3 & 49.3 \\
\hline AHHRR.25 & A1 & H4 & R5 & 8.9 \\
\hline AHHRR.25 & A1 & H4 & R6 & 39.0 \\
\hline AHHRR.25 & H3 & H4 & R5 & 48.9 \\
\hline AHHRR.25 & H3 & H4 & R6 & 10.3 \\
\hline AHHRR.25 & R5 & H4 & R6 & 38.7 \\
\hline AHHRR.25 & A1 & R5 & H3 & 89.9 \\
\hline AHHRR.25 & A1 & R5 & H4 & 159.9 \\
\hline AHHRR.25 & A1 & R5 & R6 & 64.4 \\
\hline AHHRR.25 & H3 & R5 & H4 & 89.7 \\
\hline AHHRR.25 & H3 & R5 & R6 & 26.6 \\
\hline AHHRR.25 & H4 & R5 & R6 & 116.2 \\
\hline AHHRR.25 & A1 & R6 & H3 & 80.0 \\
\hline AHHRR.25 & A1 & R6 & H4 & 56.7 \\
\hline AHHRR.25 & A1 & R6 & R5 & 32.7 \\
\hline AHHRR.25 & H3 & R6 & H4 & 23.4 \\
\hline AHHRR.25 & H3 & R6 & R5 & 48.4 \\
\hline AHHRR.25 & H4 & R6 & R5 & $25.1 ~$ \\
\hline
\end{tabular}

Table 6. Angles between different 


\section{References}

1. O.O. Fadeyi, S.T. Adamson, E.L. Myles, C.O. Okoro, Bioorg. Med. Chem. Lett. 18 (2008) 4172-4176.

2. S.A.F. Rostom, Bioorg. Med. Chem. 14 (2006) 6475-6485.

3. WHO/Cancer-World Health Organisation (2013) http://www.who.int/topics/cancer/ Accessed on 17 January 2016.

4. J.R. Sierra, V. Cepero, S. Giordano, Mol. Can. 9 (2010) 75-88.

5. S. Maayan, N. Ohad, K. Soliman Bioorg. Med. Chem. 13 (2005) 433.

6. Nowakowska, Eur. J. Med. Chem. 2007, 42, 125.

7. M.L. Go, X. Wu, X.L. Liu, Curr. Med. Chem. 12 (2005) 483.

8. V. Thomas, Mol. Plant. 3 (2010) 2-20.

9. S.K. Yazdan, G.V. Sagar, A.B. Shaik, J. Chem. Pharm. Res, 7 (2015) 829-842.

10. D.I. Batovska, I.T. Todorova, Curr. Med. Chem. 5 (2010) 1-29.

11. Sylvie D, IDrugs. 10 (2007) 42-46.

12. N.K. Sahu, S.S. Balbhadra, J. Choudhary, D.V. Kohli, Curr. Med. Chem. 19 (2012) 209225.

13. H. Aryapour, G.H. Riazi, A. Foroumadi, S. Ahmadian, A. Shafiee, O. Karima, et al. Med. Chem. Res. 20 (2011) 503-510.

14. S.A. Lahsasni, F.H.A. Korbi, N.A. Aljaber, Chem. Cent. J. 8 (2013) 1-10.

15. D.D. Jandial, C.A. Blair, S. Zhang, L.S. Krill, Y. Zhang, X. Zi, Curr. Canc. Drug Targets. 14 (2014) 181-200.

16. J. Wu, C. Wang, Y. Cai, J. Peng, D. Liang, Y. Zhao, S. Yang, X. Li, X. Wu, G. Liang, Med. Chem. Res. 21 (2012) 444-452.

17. V. Sharma, V. Kumar, P. Kumar, Anticancer. Agents. Med. Chem. 13 (2013) 422-432.

18. B. Letafat, R. Shakeri, S. Emami, S. Noushini, N. Mohammadhosseini, N. Shirkavan, S.K. Ardestani, M. Safavi, M. Samadizadeh, A. Letafat, A. Shafie, A. Foroumadi, Iran. J. Basic. Med. Sci. 16 (2013) 1155-1162.

19. Y. Tang, A.R. Simoneau, J. Xie, B. Shahandeh, X. Zi, Cancer Prev Res (Phila Pa). 1 (2008) 439-451. 
20. R. Nishimura, K. Tabata, M. Arakawa, Y. Ito, Y. Kimura, T. Akihisa, A. Sakuma, H. Kohno, T. Suzuki, Biol. Pharm. Bull. 30 (2007) 1878-1883.

21. Y. Tang, X. Li, Z. Liu, A.R. Simoneau, J. Xie, Int. J. Cancer. 127 (2010) 1758-1768.

22. A. Ivanova, D. Batovska, H. Engi, S. Parushev, I. Ocsovszki, I. Kostova, J. Molnar, In Vivo. 22 (2008) 379-384.

23. S. Ducki, D. Rennison, M. Woo, A. Kendall, J.F. Chabert, A.T. McGown, N.J. Lawrence, Bioorg. Med. Chem. 17 (2009) 7698-7710.

24. M. Cho, M. Ryu, Y. Jeong, Y.H. Chung, D.E. Kim, H.S. Cho, S. Kang, J.S. Hans, M.Y. Chang, C.K. Lee, M. Jin, H.J. Kim, S. Oh, Biochem. Biophys. Res. Commun. 390 (2009) 500-505

25. C.W. Mai, M. Yaeghoobi, N. Abd-Rahman, Y.B. Kang, M.R. Pichka, Eur. J. Med. Chem. 77 (2014) 378-387.

26. S. Syam, S.I. Abdelwahab, M.A. Al-Mamary, S. Mohan, Molecules, 17 (2012) 61796195.

27. B.T. Hieu, L.T. Thuy, V.T. Thuy, H.X. Tien, L.V. Chinh, V.D. Hoang, and T.K. Vu, Bull. Korean Chem. Soc. 33 (2012) 1586-1592.

28. Wilson AP 2000 Cytotoxicity and viability assays. In: Masters JRW, ed. Animal cell culture: a practical approach. 3rd ed. Oxford, UK: Oxford University Press; 175-219.

29. Alley, M.C. et al., Canc. Res. 48 (1998) 589.

(C) 2016 by the authors; licensee Preprints, Basel, Switzerland. This article is an open access article distributed under the terms and conditions of the Creative Commons by Attribution (CC-BY) license (http://creativecommons.org/licenses/by/4.0/). 